Louisiana State University

LSU Digital Commons

Faculty Publications

Department of Biological Sciences

8-1-2005

\title{
Phylogeny and comparative biogeography of Pionopsitta parrots and Pteroglossus toucans
}

Jessica R. Eberhard

Smithsonian Tropical Research Institute

Eldredge Bermingham

Smithsonian Tropical Research Institute

Follow this and additional works at: https://digitalcommons.Isu.edu/biosci_pubs

\section{Recommended Citation}

Eberhard, J., \& Bermingham, E. (2005). Phylogeny and comparative biogeography of Pionopsitta parrots and Pteroglossus toucans. Molecular Phylogenetics and Evolution, 36 (2), 288-304. https://doi.org/ 10.1016/j.ympev.2005.01.022

This Article is brought to you for free and open access by the Department of Biological Sciences at LSU Digital Commons. It has been accepted for inclusion in Faculty Publications by an authorized administrator of LSU Digital Commons. For more information, please contact ir@lsu.edu. 


\title{
Phylogeny and comparative biogeography of Pionopsitta parrots and Pteroglossus toucans
}

\author{
Jessica R. Eberhard *, Eldredge Bermingham \\ Smithsonian Tropical Research Institute, Apartado 2072, Balboa, Panama \\ Received 20 August 2004 \\ Available online 17 March 2005
}

\begin{abstract}
Studies of Neotropical birds, and their distributions and areas of endemism, in particular, have been central in the formulation of hypotheses proposed to explain the high species diversity in the Neotropics. We used mtDNA sequence data (ATPase 6 and 8, COI, and cyt $b$ ) to reconstruct the species-level phylogenies for two genera, Pionopsitta (Aves: Psittacidae) and Pteroglossus (Aves: Ramphastidae), compare our results with previous morphology-based phylogenetic analyses, and estimate the absolute timing of lineage and biogeographic divergences. Both the Pionopsitta and Pteroglossus phylogenies support a hypothesis of area relationships in which a divergence of the Serra do Mar (Atlantic Forest, Brazil) region of endemism is followed by the divergence of $c i s$ - and transAndean regions, then a split between the upper and lower Amazon basin, next the divergence of the Guyana area, and finally diversification of taxa in the upper Amazon basin's areas of endemism. Phylogenies of both genera support a hypothesis of area relationships that is similar to that proposed by Prum [XIX International Ornithological Congress (1988), 2562] for high-vagility species, but while they agree on the relative timing of area divergence (vicariance) events, they yield different absolute time estimates for those divergences when the typical avian mtDNA clock calibration is used. Taken at face value, the time estimates indicate that both genera began to diversify before the start of the Pleistocene, and that climatic and habitat shifts alone do not account for the diversification of these taxa.
\end{abstract}

(C) 2005 Elsevier Inc. All rights reserved.

Keywords: Neotropics; Refuge hypothesis; Systematics; Amazonia; Birds; Biogeography; Phylogeny; mtDNA

\section{Introduction}

As a group, birds are among the best-studied organisms, and analyses of their distributions and areas of endemism have been central in the formulation of hypotheses seeking to explain the high diversity of species in the Neotropics (Cracraft, 1985; Haffer, 1969, 1974). The most widely cited is the Refuge Hypothesis, which attributes most species-level diversification to cycles of fragmentation and expansion of lowland for-

\footnotetext{
* Corresponding author. Present address: Department of Biological Sciences and Museum of Natural Science, 202 Life Sciences, Louisiana State University, Baton Rouge, LA 70803, USA. Fax: +1 2255782597.

E-mail address: eberhard@1su.edu (J.R. Eberhard).
}

ests - and their associated fauna-caused by glacial cycles during the Pleistocene (Haffer, 1969; see chapters in Prance, 1982). However, the emphasis on recent (Pleistocene-era) diversification has subsequently been downplayed by a number of authors including one of the main proponents of the Refuge Hypothesis (Haffer, 1997). Emerging is a more complex view of Neotropical diversification that includes orogeny, riverine barriers, and climatological changes as mechanisms causing speciation over the last 25 million years (Bush, 1994; Cracraft and Prum, 1988). This range of mechanisms implies that biogeographic patterns will be to some extent speciesspecific, so a comprehensive understanding of diversification in the Neotropics will depend in part on the phylogeographic and phylogenetic study of organisms 
with a range of ecological requirements, population sizes, and dispersal abilities (Bates et al., 1998; Bush, 1994).

Only a handful of published studies have examined species-level phylogenetic relationships among avian taxa of the mainland Neotropics, and they indicate the importance of orogeny, particularly the rise of the Andes separating the trans-Andean (Chocó and Mesoamerica) regions of the Neotropics from the cis-Andean ones (Amazon and eastern regions of South America) (Burns, 1997; Cracraft and Prum, 1988; Hackett, 1996); the rise of the Isthmus of Panama (Hackett, 1995); riverine barriers (Bates et al., 1999; Capparella, 1988; Hackett, 1993); and climatic changes (Hackett, 1995) as probable mechanisms driving speciation. The importance of ecological gradients and parapatric speciation (Endler, 1982) for Neotropical avian diversification-was downplayed by Cracraft and Prum (1988) based on their phylogenetic

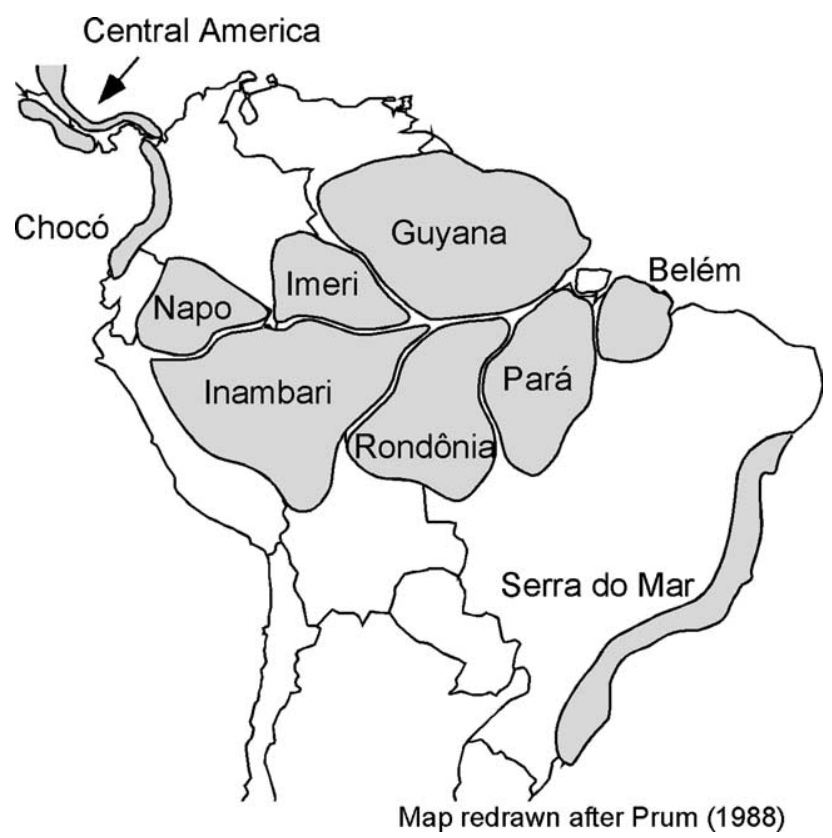

Fig. 1. Areas of endemism for Neotropical lowland forest birds, redrawn after Prum (1988). analysis of four clades of birds. Other causes of diversification-e.g., ecological heterogeneity (Tuomisto and Ruokolainen, 1995) and marine transgressions (Nores, 1999) - have been discussed in the literature, but not explicitly evaluated in phylogeographic studies of birds.

Cracraft and Prum (1988) and Prum (1988) were the first to take a phylogenetic approach, to look for concordance in geographical speciation patterns across the Neotropics, based on morphological analysis of a variety of avian taxa (see Figs. 1 and 2). Subsequent phylogenetic analyses of avian and primate datasets have led to several hypotheses, or area cladograms, of the relationships among the Neotropical areas of endemism (Bates et al., 1998; Cracraft and Prum, 1988; Prum, 1988; Silva and Oren, 1996; reviewed by Marks et al., 2002; CortésOrtíz et al., 2003). These hypotheses outline the relative timing of vicariance events that fragmented the Neotropical biota, and often posit an early split between cisand trans-Andean members of a clade (Bates et al., 1998; Cracraft and Prum, 1988; Prum, 1988). According to data representing some groups, the early cis/trans Andean split is preceded by a divergence of Serra do Mar (Atlantic Forest, Brazil) lineages, but in other groups the Serra do Mar divergence occurs later in the history of diversification (Fig. 2; Cracraft and Prum, 1988; Prum, 1988). A few genetic analyses of Neotropical birds have suggested a close area relationship between the Chocó/Central American region and the Imerí region of Amazonas (Hackett, 1993; Marks et al., 2002), but more typical is the grouping of the Imerí, Napo, and Inambari regions as a distinct Amazonas clade. In general, the historical relationships among the Amazonian regions of endemism vary considerably among the hypotheses representing different groups.

Some of the variation among area cladograms implied by different avian phylogenies may be due to differences in dispersal ability. In his analysis of 13 clades of birds from four families, Prum (1988) discerned two biogeographic patterns (Figs. 2B and C), and suggested that they reflect different responses to vicariance events
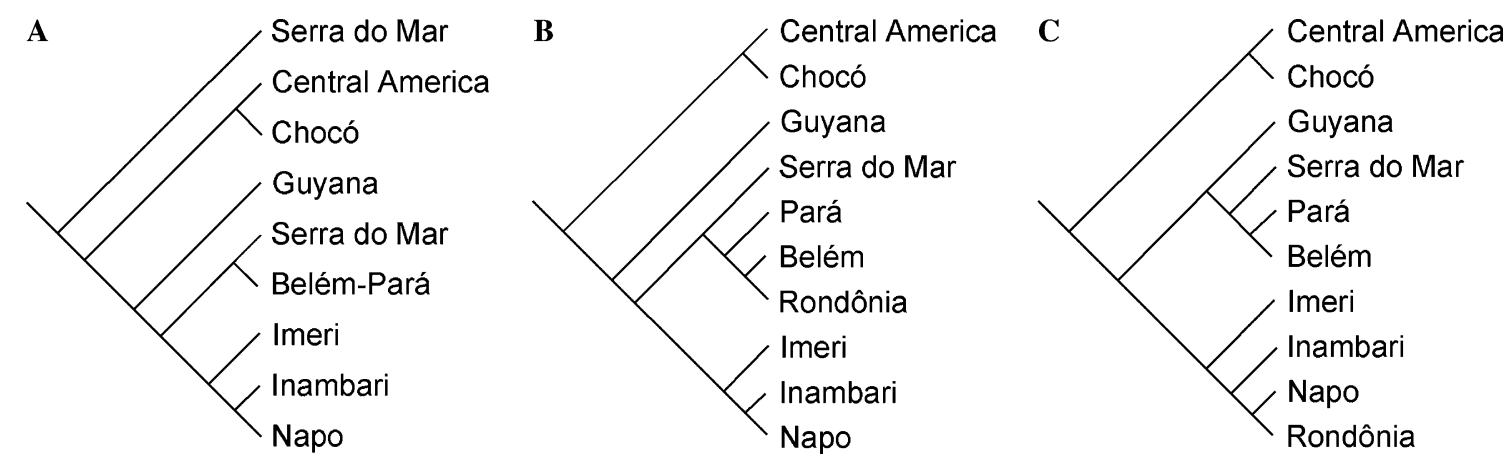

Fig. 2. Hypotheses for area relationships proposed by Cracraft and Prum (1988; a) and Prum (1988; b and c), based on phylogenetic analyses that included Pionopsitta parrots and Pteroglussus toucans. The appearance of Serra do Mar in two places in hypothesis (A) indicates that the area is a composite, or "biogeographic hybrid" (Cracraft and Prum, 1988). Hypothesis (B) was proposed for "low-vagility" species and (C) for "high-vagility" birds. 
by birds of different vagilities (dispersal ability) and population genetic structures. In general, he found that large-bodied canopy birds (e.g., Ramphastos toucans), which are presumably good dispersers, support one pattern (Fig. 2C), while smaller toucans and other forest birds, which probably have more limited dispersal abilities, support the somewhat different pattern shown in Fig. 2B. However, some taxa, namely the relatively small Pteroglossus toucans, include some species groups that support the "high vagility" pattern while other clades support the "low vagility" pattern.

The area cladograms discussed above describe the relative timing of vicariance events that shaped the biogeographic history of the Neotropics, but do not address the absolute timing of these events. Indeed, as Prum (1988) points out, some of the conflicts between biogeographic patterns shown by different taxa may simply reflect vicariance events that occurred at different times, or to cyclical changes in the permeability of barriers to dispersal over time (Bermingham and Avise, 1986). Marks et al. (2002) note that the phylogeographic pattern of the Wedgebilled Woodcreeper (Glyphorhynchus spirurus) conflicts with most hypotheses of area relationships, but that this might be due to the fact that their sample of sub-species reflects relatively recent divergences, while many arearelationship hypotheses resulted from sampling at higher taxonomic levels. Phylogenetic analyses of molecular data provide one means of estimating the absolute timing of the biogeographic events that are implied by area cladograms. Although these molecule-based time estimates are not without error (Arbogast et al., 2002; Lovette, 2004; Rambaut and Bromham, 1998; Swofford et al., 1996), they are a substantial improvement on the limited temporal information that can be obtained from morphology-based analyses in the absence of fossil data.

An estimation of absolute timing of vicariance events is particularly useful when phylogenetically independent groups are assessed for evidence of biogeographic concordance (Bermingham and Avise, 1986). Genetic studies indicate that many tropical avian taxa are older and more geographically structured than their temperate zone counterparts (Bates et al., 1999; Capparella, 1988; Hackett and Rosenberg, 1990), and taxonomic distinctions don't always reflect patterns of genetic differentiation (e.g., Marks et al., 2002; Seutin et al., 1993). Molecular data have permitted the rough estimation of divergence times for Neotropical avian taxa, and several studies (e.g., Bates et al., 1999; Capparella, 1988; Hackett, 1993; Hackett and Rosenberg, 1990) have shown species-level diversification to be pre-Pleistocene. However, in some other cases, species-level divergences appear to be Pleistocene in age (Burns, 1997; Hackett, 1995). For example, an allozyme study of Pteroglossus toucans found low levels of genetic differentiation within the genus, indicating that the group diversified fairly recently, probably during the Pleistocene (Hackett and Lehn, 1997).
In this study, we revisit the work of Cracraft and Prum (1988) and Prum (1988), using DNA sequence data to reconstruct phylogenies for two of the genera included in their studies. We compare the sequencebased phylogenies for Pionopsitta parrots and Pteroglossus toucans with the morphological phylogenies, and use the sequence data to estimate the timing of lineage divergences to refine hypotheses of the historical biogeography of these two genera.

One of the difficulties encountered when testing hypotheses of area relationships is that it is sometimes unclear which area(s) of endemism is (are) represented by each terminal taxon. The genus Pteroglossus, given the extensive sympatry of member species, is an example of this type of difficulty. Cracraft and Prum (1988) and Prum (1988) "solved" the problem by separately analyzing species groups (or "superspecies"), which were presumed to be monophyletic clades and whose member species are allopatric. Their morphology-based phylogenetic analyses allowed them to determine the relative timing of vicariant events within each clade, but the extensive sympatry among clades indicates that dispersal, and not just vicariance, was an important factor in the diversification of the group and in determining present-day distributions. The molecular phylogenetic analysis presented here includes all of the species simultaneously, which permits an evaluation of the monophyly of the above species groups, and allows a more comprehensive analysis of the historical biogeography of the genus.

\section{Methods}

\subsection{Study taxa and sampling}

Members of the genus Pionopsitta are medium-sized, stocky, short-tailed parrots typically found in lowland rainforest and tall second-growth forest, sometimes ranging into clearings with scattered trees, and in the case of some species (e.g., P. haematotis and P. pyrilia) into montane and cloud forest (Forshaw, 1989; Juniper and Parr, 1998). They feed primarily on fruits, berries, and seeds, usually in the forest canopy (Forshaw, 1989; Juniper and Parr, 1998). The genus Pionopsitta includes seven species $-P$. pileata, $P$. haematotis, $P$. pulchra, P. pyrilia, $P$. barrabandi, $P$. caica, and $P$. vulturina - that are mostly allopatric, and distributed from southern Mexico to southeastern Brazil (Forshaw, 1989; Juniper and Parr, 1998; Sibley and Monroe, 1990). Two of the species are sometimes further divided into two taxa$P$. haematotis ( $P$. haematotis and P. coccinicolaris; Cracraft and Prum, 1988) and P. barrabandi (P. barrabandi and $P$. aurantiigena; Gyldenstope, 1951). Pionopsitta vulturina, an unusual-looking parrot with a bare head that is covered with hairlike bristles instead of feathers, 
is sometimes placed in a monotypic genus, Gypopsitta (Forshaw, 1989; Sibley and Monroe, 1990). Recently, a new species, $P$. aurantiocephala, was described from Brazil (Gaban-Lima et al., 2002). It resembles P. vulturina, but has an orange rather than black head, and more extensive bare skin on the head. This new species is only known from a few localities on the Madeira and Tapajós rivers (Gaban-Lima et al., 2002), in the western part of the range depicted for P. vulturina in Fig. 6.

Pteroglossus toucans typically inhabit the canopies of lowland humid forest, second-growth woodland, and forest borders; two species ( P. flavirostris and P. castanotis) also occur in gallery forest and savanna woodland (Hilty and Brown, 1986; Meyer de Schauensee and Phelps, 1978; Ridgely and Greenfield, 2001; Ridgely and Gwynne, 1989). Examination of the stomach contents from 106 individuals in 11 Pteroglossus species indicates that these toucans are primarily frugivorous, only occasionally taking insect or vertebrate food items (Remsen et al., 1993).

In his book on the diversification of Neotropical birds, Haffer (1974) presents a detailed discussion of speciation patterns in toucans, integrating information on plumage coloration, bill morphology, voice, and geographic distribution. Haffer recognized nine Pteroglossus species, some of which he further divided into subspecies: $P$. viridis, $P$. inscriptus ( $P$. i. inscriptus and $P$. i. humboldti), P. bitorquatus (P. b. bitorquatus, $P$. b. sturmii, and $P$. b. reichenowi), $P$. flavirostris ( $P$. f. flavirostris, $P$. $f$. mariae, and $P$. f. azara), $P$. aracari, $P$. castanotis, $P$. pluricinctus, $P$. torquatus (P. t. torquatus, $P$. $t$. sanguineus, $P$. t. erythropygius, and $P$. t. frantzii), and $P$. beauharnae- sii. Haffer grouped these species into three superspecies: the $P$. viridis superspecies ( $P$. viridis and $P$. inscriptus), the $P$. bitorquatus superspecies $(P$. bitorquatus and $P$. flavirostris), and the $P$. aracari superspecies ( $P$. aracari, $P$. castanotis, $P$. pluricinctus, and $P$. torquatus). The remaining species, $P$. beauharnaesii, was considered to be a more divergent, and presumably older, species (Haffer, 1974). Haffer's classification of the genus Pteroglossus is summarized in Table 1.

Sibley and Monroe's (1990) classification differs from Haffer's, giving species status to $P$. mariae, $P$. azara (which includes Haffer's $P$. f. flavirostris and $P$. f. azara), $P$. sanguineus, $P$. erythropygius, and $P$. frantzii. The name $P$. azara (sensu Sibley and Monroe, 1990) is used by Ridgely and Greenfield (2001), but the same taxon is referred to as $P$. flavirostris by Meyer de Schauensee and Phelps (1978), as well as by Hilty and Brown (1986). The latter name is used in this paper, to facilitate comparisons with the analyses of Cracraft and Prum (1988) and Prum (1988), who use Haffer's nomenclature.

In their phylogenetic analysis, Cracraft and Prum (1988) followed Haffer's nomenclature and considered the $P$. viridis and $P$. bitorquatus species groups separately; the $P$. aracari superspecies was not included in their study. They also noted that the monotypic genus, Baillonius, appears to be the sister-group to Pteroglossus; a similar relationship is indicated by allozyme data (Hackett and Lehn, 1997).

Frozen tissue samples for this study were obtained from the tissue collections at the Philadelphia Academy of Natural Sciences (ANSP), Louisiana State University's Museum of Natural Science (LSU), the National

Table 1

Classification of Pteroglossus toucans, following Haffer's (1974) monograph

\begin{tabular}{|c|c|c|c|c|}
\hline Superspecies & Species & Subspecies & & Area \\
\hline P. viridis & $\begin{array}{l}\text { P. viridis } \\
\text { P. inscriptus }\end{array}$ & $\begin{array}{l}\text { P. i. inscriptus } \\
\text { P. i. humboldti }\end{array}$ & $\begin{array}{l}* * \\
* * \\
* *\end{array}$ & $\begin{array}{l}\text { Guyana } \\
\text { Pará } \\
\text { Inambari }\end{array}$ \\
\hline P. bitorquatus & P. bitorquatus & $\begin{array}{l}\text { P. b. bitorquatus } \\
\text { P. b. sturmii } \\
\text { P.b. reichenowi }\end{array}$ & $* *$ & $\begin{array}{l}\text { Pará } \\
\text { Pará } \\
\text { Pará }\end{array}$ \\
\hline & P. flavirostris & $\begin{array}{l}P . f . \text { flavirostris } \\
\text { P.f. mariae } \\
\text { P.f. azara }\end{array}$ & $\begin{array}{l}* * \\
* *\end{array}$ & $\begin{array}{l}\text { Imerí } \\
\text { Inambari }\end{array}$ \\
\hline P. aracari & $\begin{array}{l}\text { P. aracari } \\
\text { P. castanotis } \\
\text { P. pluricinctus } \\
\text { P. torquatus }\end{array}$ & $\begin{array}{l}\text { P.t. torquatus } \\
\text { P.t. sanguineus } \\
\text { P.t. erythropygius } \\
\text { P.t. frantzii }\end{array}$ & $\begin{array}{l}* * \\
* \\
* * \\
* * \\
* * \\
* \\
* * \\
* * \\
*\end{array}$ & $\begin{array}{l}\text { Pará } \\
\text { Rondônia } \\
\text { Imerí } \\
\text { Central America } \\
\text { Chocó } \\
\text { Chocó } \\
\text { Central America } \\
\text { Inambari } \\
\text { Serra do Mar }\end{array}$ \\
\hline
\end{tabular}

Baillonius bailloni is known to be a close relative of Pteroglossus and was a member of the ingroup in phylogenetic analyses. Taxa represented by one sample in this study are indicated by single asterisks; two asterisks indicate taxa represented by two or more samples. The area of endemism (see Fig. 1) at the center of each taxon's distribution is listed. 
Museum of Natural History (USNM), the Field Museum of Natural History (FMNH), and the University of Kansas Natural History Museum (KU). The Selenidera culik sample, used as the outgroup for Pteroglossus analyses, was contributed by J. Jennings (Emerald Forest Bird Gardens). Information pertaining to the samples, including museum catalog numbers, is provided in Table 2 . With only a few exceptions, at least two samples from each terminal taxon in the ingroups were analyzed. Some of the ANSP samples were somewhat degraded due to a freezer meltdown, but for the most part yielded useable DNA extracts; samples that produced dirty or inconsistent sequence were omitted from analyses and are not listed in Table 2. The COI fragment could not be amplified for one of the $P$. castanotis samples (Pct1641) so that sample was omitted from analyses; however the Pct1641 ATPase6,8 sequence was phylogenetically consistent with the other $P$. castanotis sample analyzed and has been deposited in GenBank. One of the P. beauharnaesii samples (Pbe9295) yielded an ATPase6,8 sequence that was phylogenetically inconsistent with the same sample's sequences from other gene regions, and with the Pbe4950 sequences; we therefore omitted Pbe9295 from the analyses, though its COI and cyt $b$ sequences have been deposited in GenBank. In addition, only the COI fragment of Pba3172, P. barrabandi, produced reliable results and is reported here. We were able to include all of the named species and subspecies of Pionopsitta except for Pi. pyrilia and the newly discovered Pi. aurantiocephala. Representatives of all of the species included in Haffer's classification of Pteroglossus were included, as well as all the subspecies belonging to Pt. inscriptus and Pt. torquatus (see Table 1).

\subsection{Laboratory methods}

Total genomic DNA was extracted from frozen tissue (blood, in the case of $S$. culik) by incubating a sample aliquot overnight in CTAB buffer (Murray and Thompson, 1980) and Proteinase K, followed by a standard phenolchloroform extraction and dialysis. Two mitochondrial DNA (mtDNA) fragments - the complete ATP synthase 6 and 8 genes (ATPase 6,8) and a 622 bp portion of cytochrome oxidase I (COI) were amplified via the polymerase chain reaction (PCR). In addition, a $694 \mathrm{bp}$ fragment of the cytochrome $b$ (cyt $b$ ) gene was sequenced for a subset of the samples (see Table 2), selected to include one member of each of the clades identified using the other two mtDNA coding regions.

The primers CO2GQL and CO3HMH (Eberhard and Bermingham, 2004) were used to amplify a 1074 bp fragment that includes the full ATPase 6 and ATPase 8 genes. The COI fragment was amplified using primers COIa and COIf (Palumbi, 1996), and the cyt $b$ fragment was amplified and sequenced using primers $\mathrm{CB} 1$ and CB3 (Palumbi, 1996). PCRs using AmpliTaq (Perkin-
Elmer) were initiated using five cycles with an annealing temperature of $50^{\circ} \mathrm{C}$ followed by 30 cycles at $56^{\circ} \mathrm{C}$.

Amplification products were run out in agarose gels to confirm that a fragment of the appropriate size had been amplified in sufficient quantity, and then cleaned and purified using GELase (Epicentre Technologies) following the manufacturer's protocol. PCR fragments were then sequenced using either Dyedeoxy or dRhodamine (Applied Biosystems/Perkin-Elmer) cycle sequencing reactions and an ABI 377 automated sequencer. The amplification primers were used for sequencing both the heavy and light strands of the PCR fragments, and an additional internal primer, A6PWL, was used to sequence the ATPase 6,8 region.

To obtain an independent molecule-based estimate of phylogenetic relationships within Pionopsitta and Pteroglossus, nuclear intron fragments from the glyceraldehyde-3-phosphate dehydrogenase (Gapdh) and Enolase genes were sequenced for a subset of samples. Primers GapdL890 and GapdH950 were used for amplification and sequencing of the Gapdh fragment, and EnoH and EnolL for the Enol fragment (Friesen et al., 1997). PCRs were done using AmpliTaq or AmpliTaq Gold (Perkin-Elmer), beginning with $5 \mathrm{~min}$ at $94^{\circ} \mathrm{C}$, followed by 30 cycles with an annealing temperature of $50{ }^{\circ} \mathrm{C}$. In some cases, the initial PCR product had to reamplified $\left(30\right.$ cycles at 50 or $56^{\circ} \mathrm{C}$ ) prior to sequencing. With the toucan samples, the Enolase primers produced two fragments; only the longer one (which showed up as a brighter band in agarose gels), was sequenced. Preliminary phylogenetic analyses of these nuclear sequences showed that they provided almost no resolution of relationships within our study genera (data not shown), so sequences were not obtained for a full complement of taxa for further analysis.

All of the mtDNA sequences have been deposited in GenBank (Accession Nos. listed in Table 2); Gapdh and Enolase intron sequences representing Pionopsitta and Pteroglossus have also been deposited (Accession Nos.: AY661261-AY661264 and AY661394-AY661402 for Gapdh; AY661241-AY661246 and AY661388AY661393 for Enolase).

\subsection{Sequence analysis}

Sequences generated by the automated sequencer were aligned and proofread using Sequencher (v.3.1.1, GeneCodes). The ATPase6,8 and COI sequences were then concatenated for initial phylogenetic analyses. Based on these analyses, a subset of samples (one representative from each terminal taxon/clade) was selected for sequencing of the cyt $b$ fragment. Phylogenies were reconstructed using the ATPase + COI dataset (which includes all samples) as well as with the ATPase + $\mathrm{COI}+$ cyt $b$ dataset (which includes single representatives of each taxon identified through analysis of the 
Table 2

Map codes (corresponding to numbers in Fig. 6), species, sample identification numbers, museum voucher numbers, and collecting localities for the Pionopsitta, Pteroglossus, and outgroup samples used in this study

\begin{tabular}{|c|c|c|c|c|c|c|c|c|c|}
\hline \multirow[t]{2}{*}{ Species } & \multirow[t]{2}{*}{ Sample ID } & \multirow[t]{2}{*}{ Sample source } & \multirow[t]{2}{*}{ Voucher number } & \multirow[t]{2}{*}{ Map code } & \multirow[t]{2}{*}{ Collecting locality } & \multicolumn{4}{|c|}{ GenBank Accession Nos. } \\
\hline & & & & & & ATPase6 & ATPase8 & $\mathrm{COI}$ & cyt $b$ \\
\hline \multicolumn{10}{|l|}{ Pionopsitta } \\
\hline \multirow{2}{*}{ P. haematotis } & Pho5768 & ANSP & 5768 & 1 & Panama: Veraguas Province & AY660908 & AY660941 & AY661224 & AY661237 \\
\hline & Pho5770 & ANSP & 5770 & 1 & Panama: Veraguas Province & AY660909 & AY660942 & AY661225 & - \\
\hline \multirow{2}{*}{ P. [h.] coccinicolaris } & Pho2185 & LSU & B-2185 & 2 & Panama: Darién Province & AY660906 & AY660939 & AY661222 & AY661236 \\
\hline & Pho2201 & LSU & B-2201 & 2 & Panama: Darién Province & AY660907 & AY660940 & AY661223 & - \\
\hline \multirow[t]{4}{*}{ P. pulchra } & Ppu2103 & ANSP & 2103 & 3 & Ecuador: Esmeraldas Province & AY660912 & AY660945 & AY661228 & - \\
\hline & Ppu2104 & ANSP & 2104 & 3 & Ecuador: Esmeraldas Province & AY660913 & AY660946 & AY661229 & - \\
\hline & Ppu2295 & ANSP & 2295 & 3 & Ecuador: Esmeraldas Province & AY660914 & AY660947 & AY661230 & AY661239 \\
\hline & Ppu2345 & ANSP & 2345 & 3 & Ecuador: Esmeraldas Province & AY660915 & AY660948 & AY661231 & - \\
\hline P. barrabandi & Pba3172 & ANSP & 3172 & 4 & Ecuador: Sucumbios Province & - & - & AY661214 & - \\
\hline \multirow[t]{2}{*}{$P .[b$.$] aurantiigena$} & $\mathrm{Pba} 4280$ & FMNH & DW-3763 & 5 & Brazil: Rondônia & AY660899 & AY660932 & AY661215 & AY661234 \\
\hline & $\mathrm{Pba} 4285$ & FMNH & DW- $-3802^{\mathrm{a}}$ & 5 & Brazil: Rondônia & AY660900 & AY660933 & AY661216 & - \\
\hline \multirow[t]{5}{*}{ P. caica } & Pca7569 & ANSP & 7569 & 6 & Guyana: Potaro-Siparuni & AY660901 & AY660934 & AY661217 & - \\
\hline & Pca7587 & ANSP & 7587 & 6 & Guyana: Potaro-Siparuni & AY660902 & AY660935 & AY661218 & - \\
\hline & Pca7638 & ANSP & 7638 & 6 & Guyana: Potaro-Siparuni & AY660903 & AY660936 & AY661219 & - \\
\hline & Pca 8290 & ANSP & 8290 & 6 & Guyana: Potaro-Siparuni & AY660904 & AY660937 & AY661220 & AY661235 \\
\hline & Pca 8547 & ANSP & 8547 & 6 & Guyana: Potaro-Siparuni & AY660905 & AY660938 & AY661221 & - \\
\hline \multirow[t]{2}{*}{$P .[G$.$] vulturina$} & Gvu6888 & USNM & 572509 & 7 & Brazil: Pará & AY660897 & AY660930 & AY661212 & AY661233 \\
\hline & Gvu6905 & USNM & 572510 & 7 & Brazil: Pará & AY660898 & AY660931 & AY661213 & - \\
\hline P. pileata & Ppi280 & KU & 88415 & 8 & Paraguay: Caazapá & AY660911 & AY660944 & AY 661227 & AY661238 \\
\hline Pionus chalcopterus & Pch2779 & ANSP & 2779 & - & Ecuador: Guayas Province & AY660916 & AY660949 & AY661232 & AY661240 \\
\hline \multicolumn{10}{|l|}{ Pteroglossus } \\
\hline \multirow[t]{2}{*}{ P. bitorquatus } & Pbt21 & FMNH & DW-3647 & 15 & Brazil: Rondônia & AY661272 & AY661309 & AY 661344 & AY661376 \\
\hline & Pbt31 & FMNH & DW-3794 ${ }^{\mathrm{a}}$ & 15 & Brazil: Rondônia & AY661273 & AY661310 & AY661345 & - \\
\hline \multirow[t]{3}{*}{ P. flavirostris } & Pffl2620 & ANSP & 2620 & 9 & Ecuador: Morona-Santiago Prov. & AY661277 & AY661314 & AY661348 & - \\
\hline & Pfl4478 & LSU & B-4478 & 10 & Peru: Loreto Department & AY661279 & AY661316 & AY661350 & AY661379 \\
\hline & Pfl27737 & LSU & B-27737 & 11 & Peru: Loreto Department & AY661278 & AY661315 & AY661349 & - \\
\hline \multirow[t]{2}{*}{ P. mariae } & Pma726 & KU & 84580 & 13 & Peru: Madre de Dios Department & AY661286 & AY661323 & AY661357 & AY661382 \\
\hline & Pma749 & $\mathrm{KU}$ & LS-243 & 13 & Peru: Madre de Dios Department & AY661287 & AY661324 & AY661358 & - \\
\hline \multirow[t]{2}{*}{ P. beauharnaesii } & Pbe4950 & LSU & B-4950 & 12 & Peru: Loreto Department & AY661270 & AY661307 & AY661342 & AY661375 \\
\hline & Pbe9295 & LSU & B-9295 & 14 & Bolivia: Pando Department & - & - & AY661343 & - \\
\hline \multirow[t]{2}{*}{ P. torquatus } & Pto3778 & ANSP & 3778 & 17 & Panama: Colón Province & AY661295 & AY661332 & AY661366 & AY661386 \\
\hline & Pto26569 & LSU & B-26569 & 17 & Panama: Colón Province & AY661294 & AY661331 & AY661365 & - \\
\hline \multirow[t]{2}{*}{$P .[t$.$] frantzii$} & Pto16075 & LSU & B-16075 & 16 & Costa Rica: Puntarenas Province & AY661292 & AY661329 & AY661363 & - \\
\hline & Pto16076 & LSU & B-16076 & 16 & Costa Rica: Puntarenas Province & AY661293 & AY661330 & AY661364 & AY661385 \\
\hline \multirow[t]{2}{*}{ P. sanguineus } & Psa2387 & ANSP & 2387 & 18 & Ecuador: Esmeraldas Province & AY661290 & AY661327 & AY661361 & - \\
\hline & Psa2403 & ANSP & 2403 & 18 & Ecuador: Esmeraldas Province & AY661291 & AY661328 & AY661362 & AY661384 \\
\hline P. erythropygius & Per3582 & ANSP & 3582 & 19 & Ecuador: Azuay Province & AY661276 & AY661313 & AY661347 & AY661378 \\
\hline P. aracari & Par7570 & ANSP & 7570 & 24 & Guyana: Potaro-Siparuni & AY661268 & AY661305 & AY661340 & AY661374 \\
\hline & Par8299 & ANSP & 8299 & 24 & Guyana: Potaro-Siparuni & AY661269 & AY661306 & AY661341 & - \\
\hline P. pluricinctus & Ppl3282 & ANSP & 3282 & 21 & Ecuador: Sucumbios Province & AY661288 & AY661325 & AY661359 & - \\
\hline & Ppl5734 & ANSP & 5734 & 20 & Ecuador: Sucumbios Province & AY661289 & AY661326 & $\begin{array}{l}\text { AY } 661360 \\
\quad \text { continue }\end{array}$ & $\begin{array}{c}\text { AY } 661383 \\
\text { n next page) }\end{array}$ \\
\hline
\end{tabular}




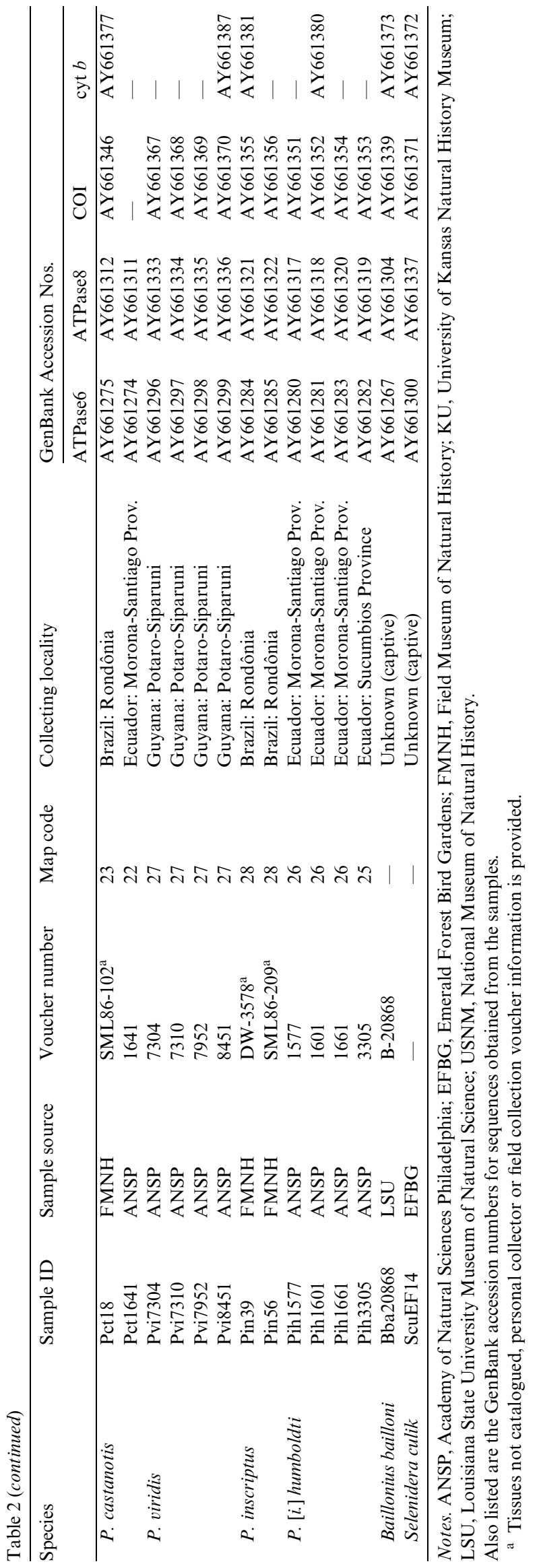

ATPase + COI dataset; see Table 2). Sequences from the different gene regions were concatenated for most phylogenetic analyses, because the mitochondrial gene regions are fully linked and thus represent a single phylogenetic marker. This was confirmed for the ATPase + COI + cyt $b$ dataset with partition-homogeneity tests, implemented in PAUP* (version 4.0b8, Swofford, 1999), of both the Pionopsitta and Pteroglossus datasets, which showed that the gene regions were not significantly heterogeneous ( $P=1.00$ and $P=0.99$, respectively).

PAUP* and Sequencer 5.0 (http://nmg.si.edu/ Sequencer.html) were used to calculate descriptive statistics about nucleotide variation. Phylogenies were reconstructed using neighbor-joining (NJ), maximum parsimony (MP), and maximum likelihood (ML) algorithms in PAUP*, as well as the Bayesian approach implemented in MrBayes (Huelsenbeck and Ronquist, 2001). The program Modeltest (Posada and Crandall, 1998) and the Akaike Information Criterion were employed to assess different models of sequence evolution, and model parameters, for the ML analyses of the ATPase $+\mathrm{COI}+$ cyt $b$ datasets. For the Pionopsitta dataset, the $\operatorname{TrN}+\mathrm{I}$ model (Tamura and Nei, 1993) was selected, with the proportion of invariant sites set to 0.69 . For the Pteroglossus dataset, the TIM $+\mathrm{I}+\mathrm{G}$ model (Rodriguez et al., 1990) was selected, with the proportion of invariant sites set to 0.68 and a gamma shape parameter of 2.0513. Outgroup rooting was used to root trees. The MP and NJ analyses were done with all characters weighted equally. Parsimony trees were found using heuristic searches and random branch addition. Neighborjoining trees were obtained using Tamura-Nei distances (Tamura and Nei, 1993). Uncorrected " $p$ " distances are presented in the text unless noted otherwise, to interpret genetic divergence in the context of the original avian molecular clock calibrations (Shields and Wilson, 1987; Tarr and Fleischer, 1993).

For the Bayesian Markov chain Monte Carlo searches, a general time-reversible model was specified, with site-specific variation partitioned by codon position. Four chains were run for 5,000,000 generations and sampled every 1000 generations. In both the Pionopsitta and Pteroglossus analyses, stationarity was reached by 10,000 generations, so the first 10,000 generations were discarded, and the remaining trees were used to obtain a majority-rule consensus.

Nodal support was assessed by bootstrap analysis in the MP, NJ, and ML analyses (1000, 10,000, and 100 bootstrap replicates, respectively), and posterior probabilities in the Bayesian analyses. The posterior probabilities indicate the proportion of the time that a given clade occurs among the trees sampled in the Bayesian analyses (Huelsenbeck and Ronquist, 2001). Alternative topologies of the Pteroglossus tree were compared using the non-parametric Shimodaira-Hasegawa $(\mathrm{S}-\mathrm{H})$ test (Shimodaira and Hasegawa, 1999) in PAUP*, using RELL 
bootstrapping (1000 replicates) and the likelihood parameters used in the ML analyses.

Because of differences between the parrot and toucan clades regarding the timing of area divergences (see Section 3), we also examined rates of synonymous and nonsynonymous substitution in the two genera. For each genus, $K_{\mathrm{A}}$ (the number of non-synonymous substitutions per non-synonymous site) and $K_{\mathrm{S}}$ (the number of synonymous substitutions per synonymous site) were calculated for all of the pairwise species comparisons, using the method of Li (1993) and Pamilo and Bianchi (1993) as implemented in Sequencer.

\subsection{Biogeographic analysis}

The Pionopsitta and Pteroglossus phylogenies were used to estimate the timing - both relative and absolute - of vicariance events hypothesized to have caused phylogenetic divergences. The current distributions of taxa (see Fig. 6) were used to determine the area(s) of endemism (see Fig. 1). A taxon was assigned to the region (or regions) of endemism most broadly overlapping the central part of its distribution. These taxon-area associations are summarized in Table 1, and resulted in area cladograms that could be compared with the hypotheses of area relationships proposed by Prum (1988) and Cracraft and Prum (1988) for the same genera (Fig. 2). This approach makes the simplifying assumption that the contemporary geographic ranges of species are similar to those of their ancestors. Given the lability of geographic ranges, this assumption can be problematic (Losos and Glor, 2003), as discussed below.

Based on the area relationships suggested by our Pionopsitta and Pteroglossus area cladograms, we constructed a general area cladogram. This area hypothesis was used as a framework in which to examine our phylogeny-based estimates of the absolute timing of vicariance events. The nodes on our area cladogram were numbered sequentially with 1 indicating the earliest vicariance event. Using this numbering scheme, the nodes on the Pionopsitta and Pteroglossus phylogenies were then numbered such that all nodes indicating the same putative vicariant event (e.g., separation of the cisfrom the trans-Andean areas) have the same number. For each of the numbered nodes on the phylogenies, we calculated the mean genetic distance (based on the ATPase $+\mathrm{COI}+$ cyt $b$ dataset) between taxa spanning that node. The distances were then plotted against node number, to compare the genetic divergences in geographically matched pairs of Pionopsitta and Pteroglossus lineages.

We used the observed genetic distances to estimate the time at which lineages diverged, under the assumption that mitochondrial DNA accumulates base changes at a clock-like rate. For both the Pionopsitta and Pteroglossus ATPase $+\mathrm{COI}+$ cyt $b$ datasets, the assumption of clock-like sequence change was first tested by using a Likelihood Ratio Test (LRT; Felsenstein, 1981) to compare the likelihood scores of ML trees found by heuristic searches in PAUP* with a molecular clock enforced vs. not enforced. The LRTs were done using ModelTest v.3.1 (Posada and Crandall, 1998). Within the genus Pionopsitta (i.e., excluding the outgroup, Pionus), the parrot sequences have evolved at a clock-like rate, as indicated by the lack of statistical difference between trees found with vs. without a clock enforced $(P=0.11)$. A similar test using the Pteroglossus data (excluding $S$. culik) also indicates clock-like sequence evolution within the genus $(P=0.06)$. A molecular clock calibration is not available for either parrots or toucans, so we used a $2 \%$ divergence per million years (my) calibration that has been found to hold for other birds (geese , Shields and Wilson, 1987; Hawai'ian honeycreepers, Tarr and Fleischer, 1993; but see Lovette, 2004).

As an alternative way to evaluate the concordance between our phylogenetic data and our proposed area hypothesis, we reconstructed the history of each genus' biogeographic associations using TreeMap (Page, 1995). This program uses the reconciled trees approach (Page, 1994) to reconstruct the historical associations between the bird lineages and geographic areas, given a phylogeny for the bird genus and a cladogram representing hypothesized area relationships, with each terminal taxon assigned to an area of endemism as described above (see Table 1). The method maximizes the number of vicariance events (or "co-speciation events" in a host-parasite framework) and permits lineage duplication, but does not accommodate dispersal (Page and Charleston, 1998). The significance of the observed fit between the bird and area cladograms was evaluated with a randomization test implemented in TreeMap. The randomizations were performed using the proportional-to-distinguishable model, and statistical significance was determined by comparing the observed number of vicariance events with the histogram of expected vicariance frequencies generated by the randomization.

As in other biogeographic studies that have taken an approach similar to ours, the use of phylogenetic data to reconstruct area relationships assumes that the organisms in question have undergone allopatric speciation. Although this assumption is difficult to test, we followed methods outlined by Barraclough and Vogler (2000) to determine whether our data are consistent with an allopatric mode of speciation. Distribution maps for the species included in our study were drawn to the same scale, and a grid superimposed on the map was used to estimate the area (in grid units) of each species' range. For each sister clade in the phylogeny, the degree of sympatry was calculated as the area of overlap divided by the range size of the clade with the smaller range. The resultant values range from 0.0 to 1.0 , and were plotted 
against the genetic distances between corresponding sister clades (see Barraclough and Vogler, 2000).

\section{Results}

\subsection{Phylogeny of Pionopsitta}

Phylogenetic analysis of the 2168 bp ATPase + COI + cyt $b$ Pionopsitta dataset yielded trees with identical topologies, regardless of the reconstruction algorithm used. The ML tree shown in Fig. 3 is topologically identical to the single tree found in an exhaustive parsimony search, and is also identical to the Bayesian tree, as well as neighbor-joining trees reconstructed using a variety of distance corrections (not shown). Bootstrap and posterior probability values show high support for all nodes. Pionopsitta pileata, from the Atlantic forests of southeastern Brazil, diverges early in the history of the genus. Pionopsitta [Gypopsitta] vulturina falls well within the genus Pionopsitta, and is sister to $P$. caica. Since only a COI sequence was obtained for the $P$. $b$. barrabandi sample, it could not be included in the ATPase + COI + cyt $b$ dataset, but its position according to analysis of the COI

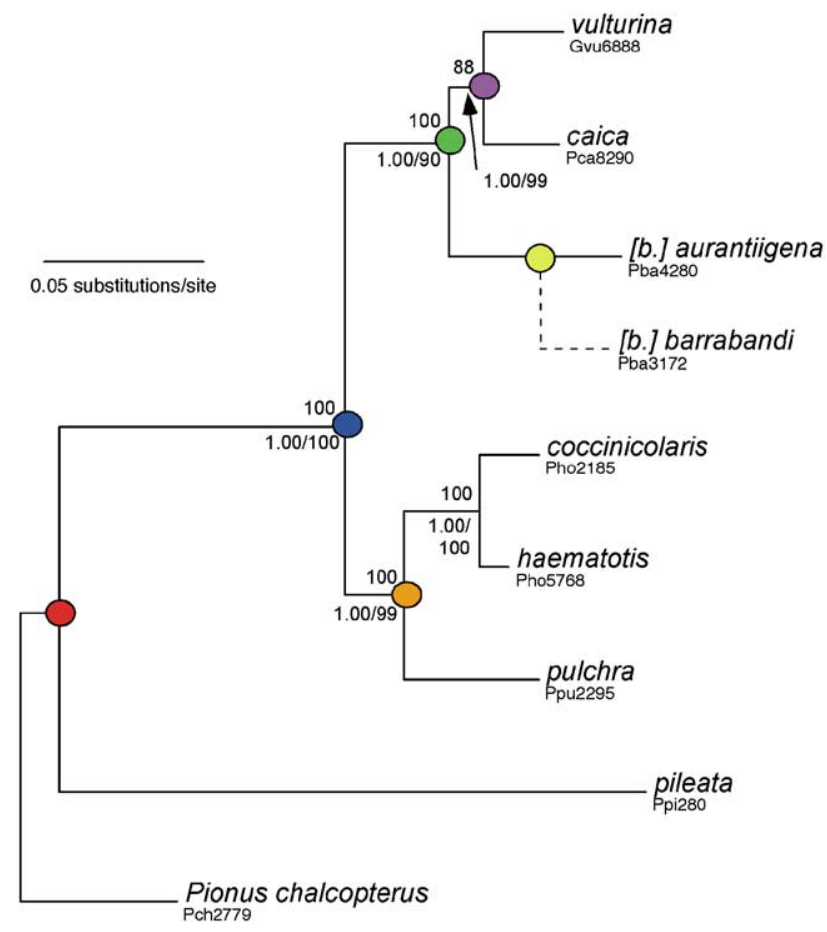

Fig. 3. Phylogenetic tree for Pionopsitta parrots obtained in a maximum likelihood analysis of the 2168 bp ATPase + COI + cyt $b$ dataset. A topologically identical tree was obtained in a Bayesian analysis, and an exhaustive parsimony search found a single most parsimonious tree with the same topology. Values above the nodes are maximum likelihood bootstrap values (100 replicates); values below the nodes are Bayesian posterior probability values, followed by parsimony bootstrap values (1000 replicates). The phylogenetic position of $P$. [b.] barrabandi according to the COI data is indicated with a dotted line (see text). Nodes are color-coded to correspond with Figs. 5-7. data is indicated in Fig. 3. In phylogenies reconstructed using only the COI data (not shown), the node connecting $P . b$. barrabandi and $P$. b. aurantiigena is well-supported in bootstrap analyses (96 and 98\% for neighbor-joining and parsimony trees, respectively), and the taxa show $1.5 \%$ sequence divergence in COI.

Across the board, P. pileata is more diverged from the other Pionopsitta taxa than is the outgroup, Pionus chalcopterus. This is true even if a Tamura-Nei correction is used in calculating pairwise genetic distances. Furthermore, the genetic distance between $P$. pileata and Pionus $(11.1 \%)$ is less than any of the distances between P. pileata and other Pionopsitta taxa (range: 12.8 $13.6 \%$ ). Excluding $P$. pileata, the genetic distances between Pionopsitta taxa, calculated with the ATPase + COI + cyt $b$ dataset, range from $2.4 \%(P . h$. haematotis vs. $P$. h. coccinicolaris) to $9.1 \%$ (P. pulchra vs. $P$. barrabandi and $P$. [G.] vulturina), with a mean distance of $7.0 \%$. The mean divergence between Pionopsitta taxa (excluding $P$. pileata) and the outgroup, $P$. chalcopterus, is $10.8 \%$. The divergence of $P$. pileata is also reflected in the Enolase (nuclear intron) sequence data; the mean distance between $P$. pileata and two other Pionopsitta species for which the intron was sequenced (barrabandi and caica) is 6.4\%, while the mean distance between $P$. chalcopterus and those species is only $3.1 \%$.

\subsection{Phylogeny of Pteroglossus}

Analysis of the ATPase $+\mathrm{COI}+$ cyt $b$ Pteroglossus dataset using Bayesian, MP, ML, and distance algorithms produced well-supported phylogenetic trees that are topologically consistent with each other. The topology of the ML tree shown in Fig. 4 is nearly identical to the Bayesian tree and the consensus of the two best MP trees (the only difference being in the relationships within the aracari/castanotis/pluricinctus clade). Of the three superspecies described by Haffer (1974; see Table 1 ), only the viridis group is shown to be monophyletic according to the sequence data. The aracari and bitorquatus groups are polyphyletic, and $P$. beauharnaesii, which Haffer thought to be systematically isolated, is closely allied to the members of the bitorquatus superspecies. Genetic distances between taxa in the Pteroglossus clade, calculated with the ATPase + COI + cyt $b$ dataset, range from $0.5 \%$ ( $P$. mariae vs. $P$. flavirostris) to $7.9 \%$ ( $B$. bailloni vs. $P$. torquatus), and the mean divergence between Pteroglossus species and the outgroup, S. culik, is $11.5 \%$.

In all analyses, $B$. bailloni falls within the Pteroglossus clade, sister to the species that compose Haffer's (1974) $P$. viridis superspecies. This node, which places $B$. bailloni within Pteroglossus rather than sister to it, receives moderate support $(91 \%$ bootstrap support in the ML analysis, 0.67 posterior probability in the Bayesian analysis, and $88 \%$ bootstrap support in the parsimony 


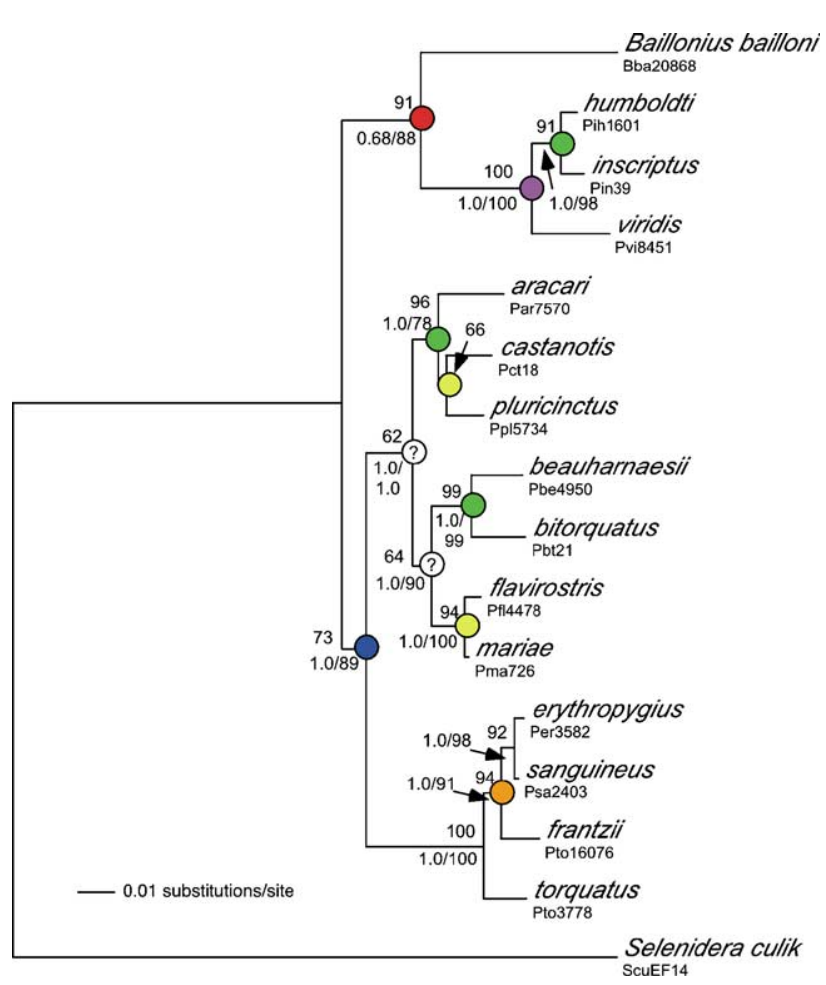

Fig. 4. Phylogenetic tree for Pteroglossus toucans obtained in a maximum likelihood analysis of the $2168 \mathrm{bp}$ ATPase + COI + cyt $b$ dataset. The trees obtained in a Bayesian analysis differ only in the relationships within the aracari/castanotis/pluricinctus clade; a heuristic parsimony search found two most parsimonious trees that are nearly identical to the one shown, differing only in relationships within this same clade. Values above the nodes are maximum likelihood bootstrap values (100 replicates); values below the nodes are Bayesian posterior probability values, followed by MP bootstrap values (1000 replicates). Only a likelihood bootstrap value is given for the castanotis/plurinctus clade, since it was not retained in the Bayesian and parsimony bootstrap analyses, which grouped aracari and castanotis with weak support (70 and 54 in the Bayesian and parsimony analyses, respectively). Nodes are color-coded to correspond with Figs. 5-7.

analysis). While this result is consistent across reconstructions, our data do not permit us to reject an alternative tree topology that places $B$. bailloni outside, and sister to, the Pteroglossus clade. Using an $\mathrm{S}-\mathrm{H}$ test to compare the tree shown in Fig. 4 with a tree in which B. bailloni is sister to the Pteroglossus clade, there is no significant difference between the two topologies $(P=0.159)$.

\subsection{Biogeography of Pionopsitta and Pteroglossus}

The genus Pteroglossus is much more speciose than Pionopsitta and a number of Pteroglossus species occur in sympatry, complicating the reconstruction of the toucans' biogeographic history. Nonetheless, a number of biogeographic concordances are immediately evident in a comparison of the phylogenies representing the two genera. In both cases, the isolation of lineages restricted to the Serra do Mar area of endemism occurs early. This is followed by a vicariance event that separates the cis- and trans-Andean lineages. In Pionopsitta, the next divergence is between lineages from upper and lower Amazon basin, followed by divergence of the Guyana shield species and divergence of lineages from the northern and southern banks of the upper Amazon River. At approximately the same time as the upper/lower Amazonian vicariance, the Chocó and Central American lineages diverge. The timing of divergence events among cis-Andean Pteroglossus is less clear, because the sympatry among taxa makes it difficult to assign taxa to particular areas of endemism.

The sequence of vicariance events suggested by our Pionopsitta and Pteroglossus phylogenies are consistent with the area hypothesis shown in Fig. 5, with the exception of the isolation of Pteroglossus viridis in the Guianan region, which precedes the upper/lower Amazonian vicariance within the viridis clade. The phylogenetic placement of Pteroglossus aracari indicates that representatives of this lineage arrived relatively recently to the Serra do Mar region. The hypothesized vicariance events outlined in Fig. 5 are also shown relative to the current distributions of Pionopsitta and Pteroglossus taxa in Fig. 6.

The concordance between the area hypothesis in Fig. 5 and our phylogenetic data are illustrated in Fig. 7, which shows the genetic divergences at geographically matched nodes in the phylogenies of the two genera. Corresponding geographic splits are indicated by color coding that is consistent across figures. In the graph, the nodes are ordered according to the area cladogram shown in Fig. 5. Because of the uncertainties of area assignment (see Section 2) in Pteroglossus, and to a lesser extent in Pionopsitta, some of the nodes are represented by multiple points in Fig. 7. This results in some scatter, particularly for nodes $3-5$, which are the most likely to be affected by errors of area assignment due to sympatry resulting from dispersal and recolonization following allopatric speciation. Although the $x$-axis in the graph is ordinal rather than continuous, the degree of "linearity" of the parrot and toucan distances indicates the degree to which the genetic distance data fit the area hypothesis used to generate the plot. The genetic distance data were also plotted according to the alternative area cladograms shown in Fig. 2, and in all cases the plots showed poorer fits of the distance data to the area hypotheses (not shown). A striking result that is illustrated in Fig. 7 is that for matched geographic splits (inferred vicariance events), the genetic divergences between Pionopsitta lineages are consistently greater than the divergences observed in Pteroglossus. This difference is statistically significant (two-way ANOVA: effect of genus on genetic divergences across all nodes, $P<0.0001$ ).

The molecular genetic distances estimated with the parrot and toucan data were used to estimate the time at which the different geographic divergences occurred. Under the assumption of a common molecular "clock" 

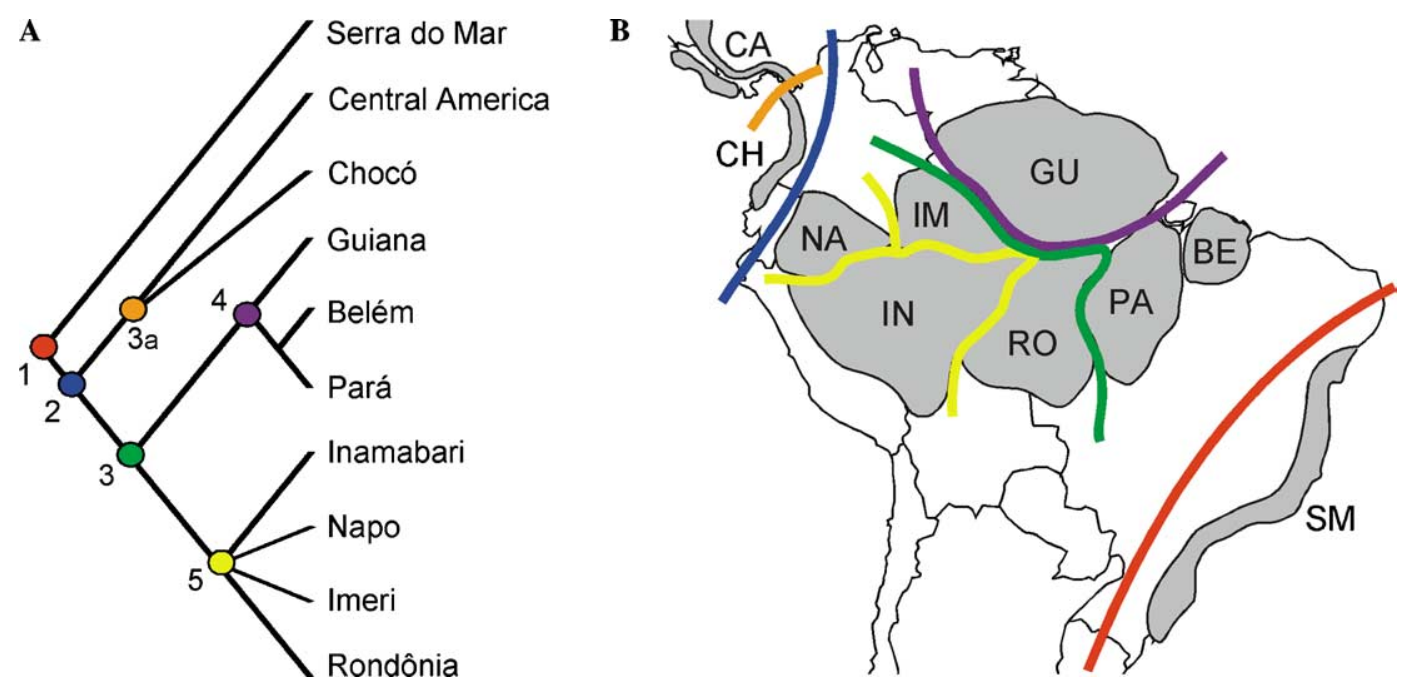

Fig. 5. Cladogram (A) and map (B) of area relationships that are consistent with the Pionopsitta and Pteroglossus phylogenies. The nodes of the cladogram that represent major vicariance events are numbered according to the hypothesized order of occurrence, and color-coded to correspond to the geographical splits indicated in the map.

calibration, the parrot data suggest that the biogeographic breaks are much older than would be estimated based on the toucan data. This discrepancy is greater (by as much as a factor of two) for the older biogeographic breaks and negligible for the more recent ones (Fig. 7). Using the typical avian calibration $(2 \%$ sequence divergence per my), the Pionopsitta data suggest that the Serra do Mar fauna became isolated from its Amazonian relatives approximately 6.6 mya, while the Pteroglossus data suggest that this divergence occurred 3.1 mya. The divergence between cis- and trans-Andean taxa is estimated to have occurred 4.2 and 2.6 mya according to the parrot and toucan data, respectively. In both genera, the data suggest that the most recently derived species arose within the past million years.

To further explore the difference between the levels of divergence observed in the two genera, we compared $K_{\mathrm{A}}$ and $K_{\mathrm{S}}$ between the two genera. Both types of substitution were significantly more frequent in Pionopsitta $(t$ test: $t_{\mathrm{S}}=5.142, \mathrm{df}=146, \quad P<0.0001$ and $t_{\mathrm{S}}=6.322$, $\mathrm{df}=146, P<0.0001$ for $K_{\mathrm{A}}$ and $K_{\mathrm{S}}$, respectively). The mean $K_{\mathrm{A}} / K_{\mathrm{S}}$ across all the pairwise Pionopsitta comparisons was 0.091 , and slightly but not significantly lower (0.086) for Pteroglossus ( $t$ test: $t_{\mathrm{S}}=0.749, \mathrm{df}=146$, $P=0.4552$ ). However, the rate at which non-synonymous substitutions accumulate relative to synonymous ones is greater in Pteroglossus than in Pionopsitta (Fig. 8 ). This difference is significant, since the $95 \%$ confidence intervals for the slope of the two regression lines do not overlap (0.1045-0.1209 and 0.0658-0.0914 for Pteroglossus and Pionopsitta, respectively). The difference between the two slopes is also significant if a reduced dataset is used, including only the pairwise comparisons between a single taxon from each genus and the other members of its genus (data not shown).
The TreeMap reconstructions show a strong correspondence between the area cladogram shown in Fig. 5 and both the Pionopsitta and the Pteroglossus phylogenies, given current distributions. A reconciled tree reconstruction for Pionopsitta and the area cladogram includes six vicariance events $(P<0.0001)$. Using the area assignments shown in Table 1 , a reconciled tree reconstruction for Pteroglossus includes seven vicariance events $(0.05<P<0.76)$. However, given that it was difficult to determine the appropriate area assignment for two Pteroglossus taxa-bitorquatus and inscriptus - that bridge one of the older geographic splits in Fig. 5, significance was also tested under alternative area assignments for these two taxa. If bitorquatus is assigned to Rondonia (instead of Pará), seven vicariance events are reconstructed $(0.05<P<0.065)$; if inscriptus is assigned to Rondônia (instead of Pará), eight vicariance events are reconstructed $(P<0.012)$.

Plots of the degree of sympatry (range overlap) against genetic distance between sister species/clades show that in both Pionopsitta and Pteroglossus, recently diverged lineages are allopatric (Fig. 9). In Pteroglossus, sympatry is only observed between older lineages, and the increase in sympatry with increasing genetic distance suggests that range changes have occurred over time, implying dispersal following speciation events. In contrast, even the relatively old Pionopsitta lineages maintain allopatry.

\section{Discussion}

\subsection{Phylogeny of Pionopsitta and Pteroglossus}

In general, our molecular phylogeny for Pionopsitta is in agreement with the morphology-based phylogeny 
A

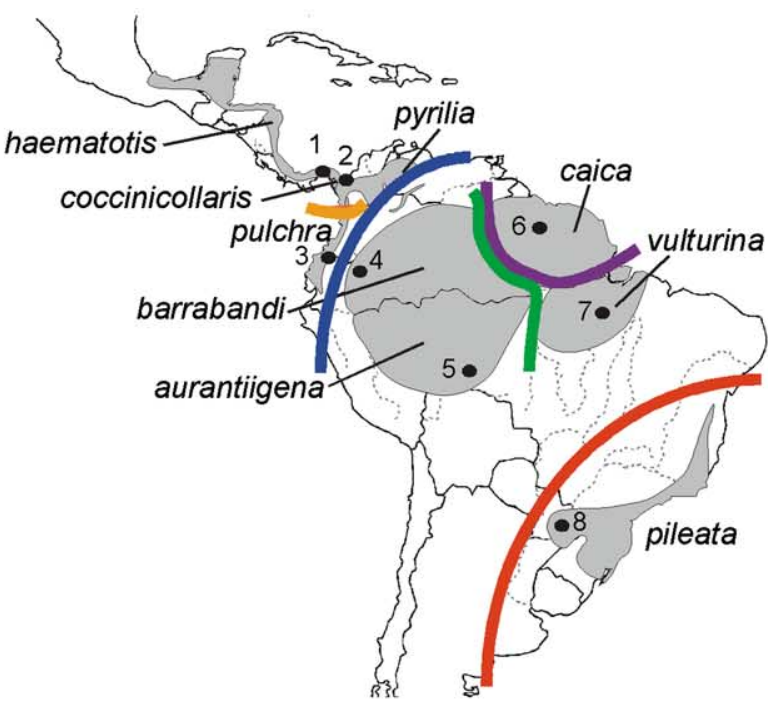

C

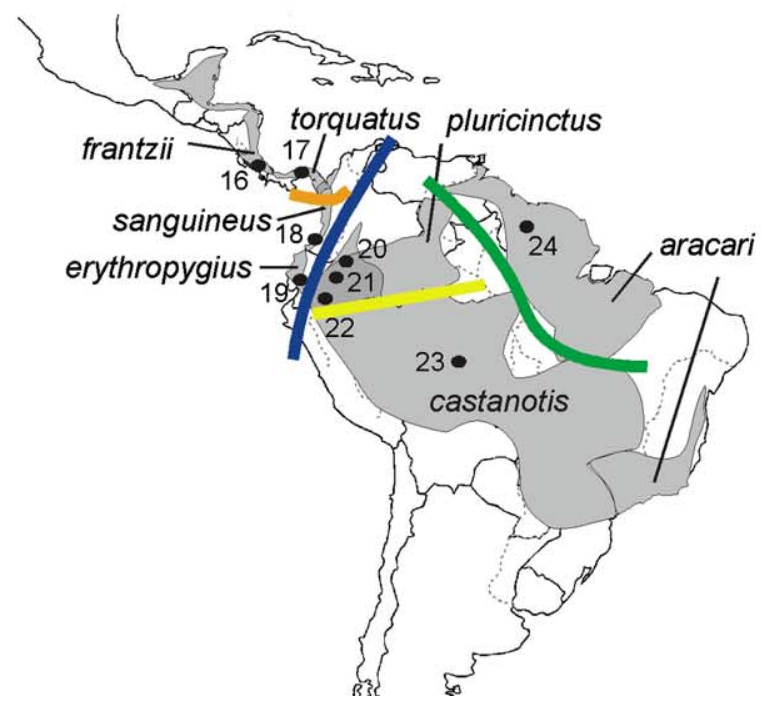

B

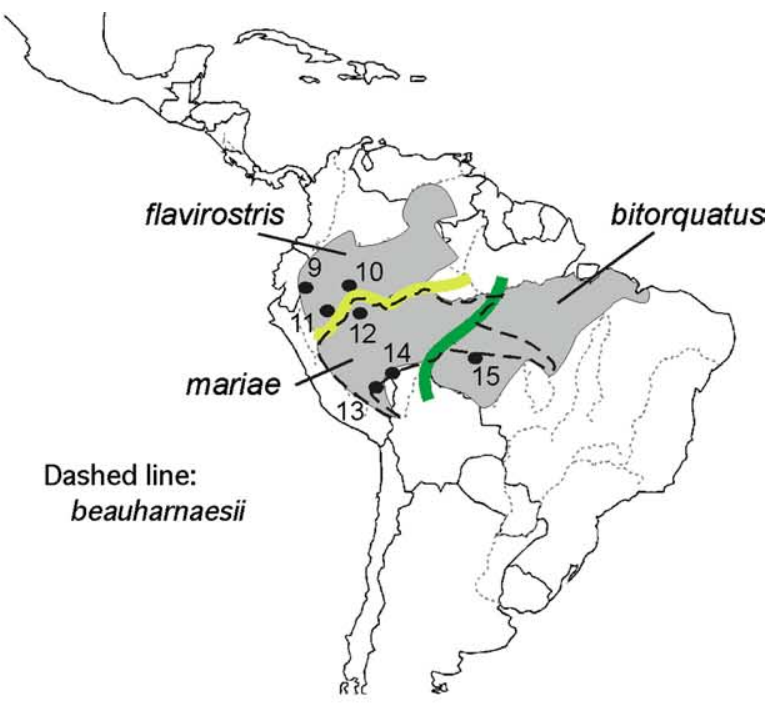

D

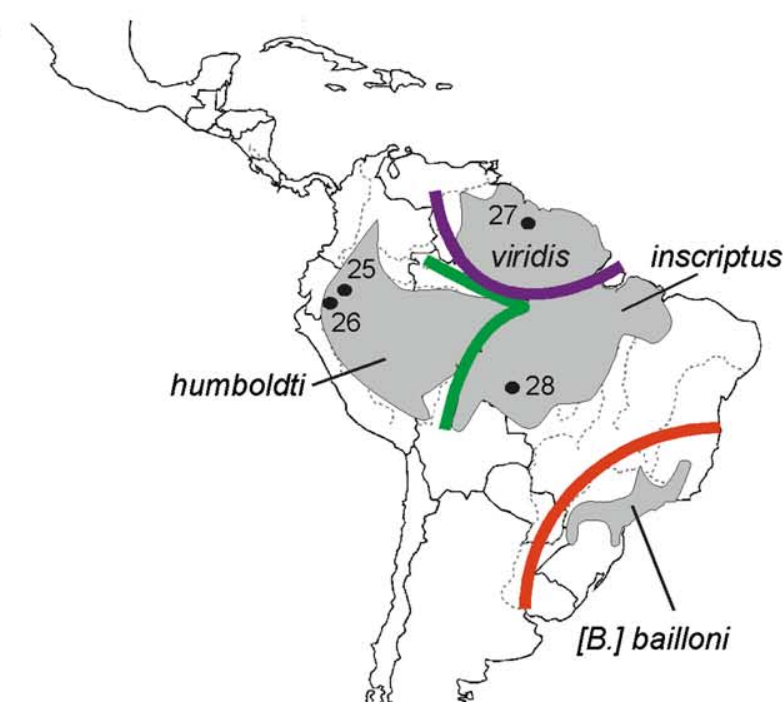

Fig. 6. Distributions of Pionopsitta parrots (A) and Pteroglossus toucans (B-D). Colored lines indicate vicariance events that are hypothesized to have resulted in phylogenetic divergences, and are color-coded to correspond to the area hypothesis in Fig. 5. Note. Colored lines were drawn along current distributional limits, and do not necessarily coincide with the location of the hypothesized barrier or exact limits between regions of endemism implicated in the hypothesized vicariance event.

presented by Cracraft and Prum (1988). Both analyses support a basal placement of pileata, an early split between cis- and trans-Andean species, and the datasets agree in the relationships among trans-Andean species. Our phylogeny differs from theirs in finding vulturina and caica to be sister taxa (the morphological analysis has barrabandilaurantiigena as sister to vulturina, with caica basal to a barrabandilaurantiigena + vulturina + pyrilia clade). The genetic distance data indicate that pileata is not closely related to the other Pionopsitta species, and is separated from them by distances as large as those extending to the outgroup genus, Pionus. This accords well with Forshaw's (1989) description of pileata as "a rather aberrant species" that is set apart from the rest of the genus by a number of morphological characteristics: presence of sexual dimorphism, a bill that is less projecting and not laterally compressed towards the tip, a proportionately longer tail, narrower tail feathers, and wings that are narrower and more pointed.

In their analysis of Pteroglossus, Cracraft and Prum (1988) followed Haffer (1974) in considering the viridis superspecies group to be monophyletic, and this is supported by our data. However, Haffer's (1974) bitorquatus and aracari clades are not monophyletic according to the mtDNA phylogeny. Our molecular data place beauharnaesii within the bitorquatus group, which is itself within a larger clade that includes the members of Haffer's aracari superspecies. The close relationship between beauharnaesii and bitorquatus agrees with the allozyme data of Hackett and Lehn (1997), however, their data also placed inscriptus in the same clade as these two species. Hackett and Lehn's analysis also 


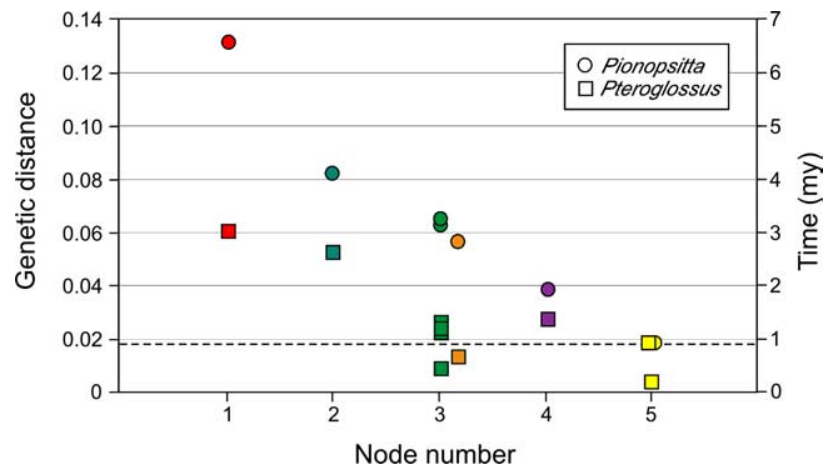

Fig. 7. Genetic divergences (uncorrected " $p$ " distances calculated using the ATPase + COI + cyt $b$ dataset) for geographically matched taxon pairs. Points are color-coded to correspond to the nodes and geographic divergences illustrated in Figs. 5 and 6. The Pionopsitta distance for node 5 (aurantiigena vs. barrabandi), is COI only (see text). An estimated time scale ( $2 \%$ sequence divergence per my) is shown on the right vertical axis, and a dashed line at 0.9 my indicates the time at which late-Pleistocene glacial cycles began (Stanley and Ruddiman, 1995; Webb and Bartlein, 1992).

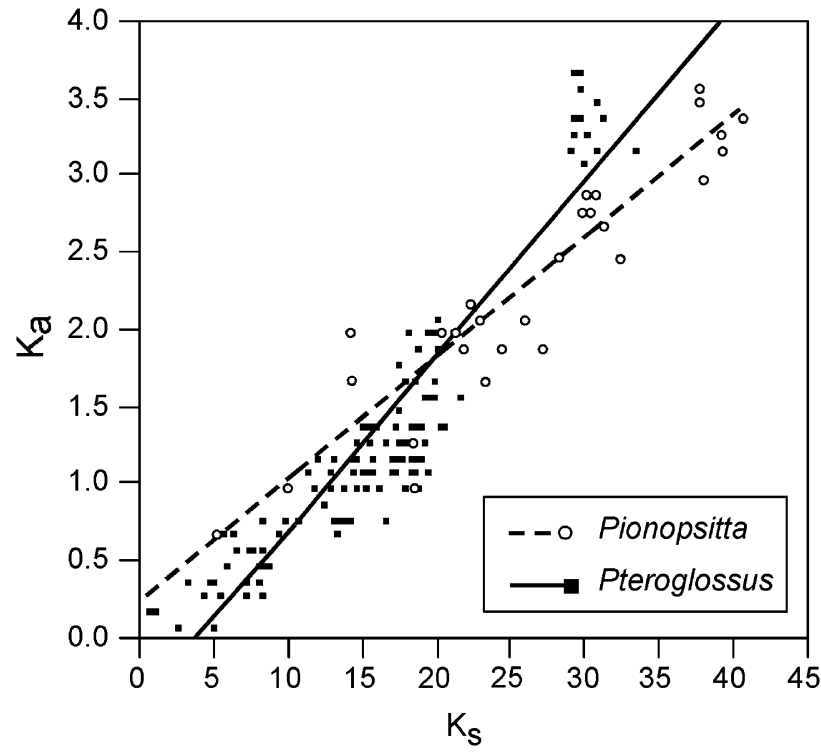

Fig. 8. Number of synonymous substitutions per synonymous site $\left(K_{\mathrm{S}}\right)$ and non-synonymous substitutions per non-synonymous site $\left(K_{\mathrm{A}}\right)$ for all pairwise comparisons in the ATPase + COI + cyt $b$ dataset for Pionopsitta (circles) and Pteroglossus (squares). Distances were calculated using the method of Li (1993) and Pamilo and Bianchi (1993). Regression lines are drawn through the points for each of the genera; the $95 \%$ confidence intervals around the slopes are non-overlapping, indicating that they are significantly different (see text).

separated mariae and flavirostris, which, as they point out, conflicts with the similarity in these birds' plumage; our sequence data show that mariae and flavirostris are closely related. Like Prum (1988) and Hackett and Lehn (1997), we found the trans-Andean species to be monophyletic, and the Chocó species ( $P$. sanguineus and $P$. erythropygius) to be sister taxa. Other authors (Barker and Lanyon, 2000; Cracraft and Prum, 1988; Hackett and Lehn, 1997; Haffer, 1974) have consistently pointed

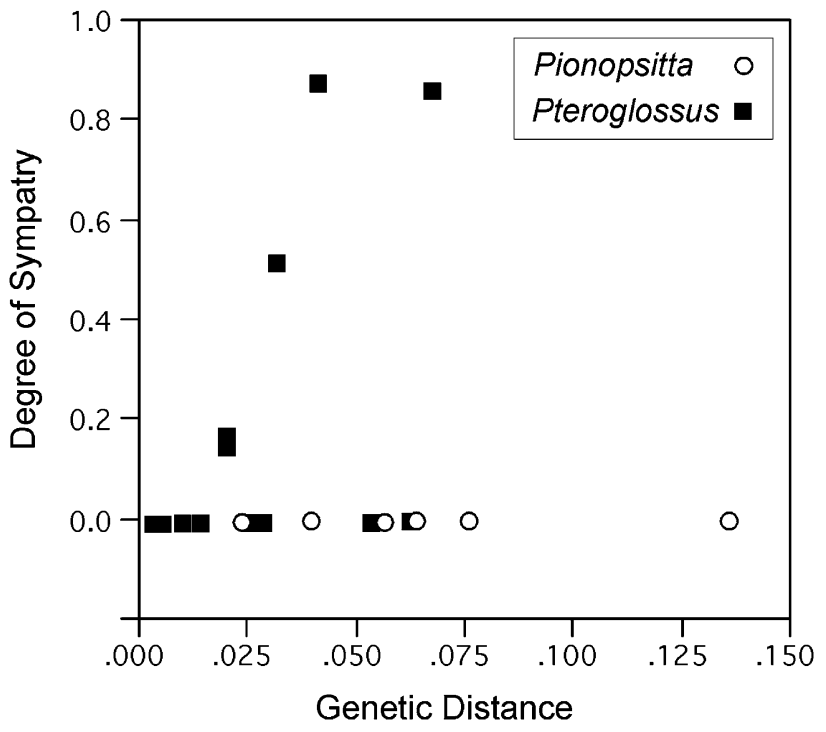

Fig. 9. Plots of the degree of sympatry against relative node age in Pionopsitta parrots (circles) and Pteroglossus (squares). Degree of sympatry was defined as the proportion of the more restricted species or clade's range overlapped by its more widespread sister species or clade. The relative node age was defined as the genetic distance ( $p$ distance) between the species or clades being compared.

out the close relationship between Baillonius and Pteroglossus; according to the sequence data, B. bailloni falls within, rather than sister to, the genus Pteroglossus with moderate nodal support. The sequence data alone, however, do not allow us to reject the traditional placement of $B$. bailloni as sister to the Pteroglossus, so we hesitate to recommend referring $B$. bailloni to the genus Pteroglossus.

\subsection{Biogeography of Pionopsitta and Pteroglossus}

Both the Pionopsitta and Pteroglossus phylogenies support a hypothesis of area relationships in which a divergence of the Serra do Mar region of endemism is followed by the divergence of cis- and trans-Andean regions, then a split between the upper and lower Amazon basin and divergence of the Choco and Central American lineages, next the divergence of the Guyana area, and finally diversification of taxa in the upper Amazon basin's areas of endemism. This area hypothesis is similar to the "high vagility" hypothesis proposed by Prum (1988), modified by placing the Serra do Mar split to be the earliest. An early Serra do Mar split is consistent with one of the alternative placements of this area in Cracraft and Prum's (1988) hypothesis (see Fig. 2A), which considers Serra do Mar to be a biogeographic composite with an avifauna comprising taxa with different biogeographic histories. An early Serra do Mar split was also hypothesized by Bates et al.'s (1998) study of 1717 Neotropical lowland avian taxa. The observation that recently diverged lineages show low levels of range 
overlap (Fig. 9) is consistent with our proposed area hypothesis, which implicates vicariance (allopatric divergence) as a primary mechanism for diversification in these genera. However, the difference between genera in the estimated time of hypothesized vicariance events suggests that either (1) the genera diversified as a result of different vicariance events (or other processes) that occurred at different times in the two groups, (2) differential responses to the same vicariant events, or (3) the genera differ markedly in their rates of sequence evolution and/or lineage sorting rates.

The concordance between the Pionopsitta and Pteroglossus data in the sequence - the relative chronology - of inferred biogeographic separation strongly suggests that the same vicariance events underlie major divergences in both genera. However, the absolute time estimates for any given split are quite different for the two datasets. The genetic distances, and estimated time since divergence, between geographically matched lineages are consistently smaller in the toucans. This agrees with Hackett and Lehn's (1997) allozyme study of Pteroglossus, which noted low levels of genetic differentiation among species in the genus. Several hypotheses, which are not mutually exclusive, might account for this discrepancy: (1) the rate of mtDNA sequence evolution in Pteroglossus is slower than in Pionopsitta, possibly due to differing selection on mtDNA in the two groups; (2) because of ecological or behavioral differences, birds in the two genera may respond differently to the presence of a geographic barrier; and (3) within species, Pionopsitta populations may be more geographically structured than Pteroglossus, resulting in more rapid lineage sorting and greater genetic divergence following vicariance events (Edwards and Beerli, 2000; Hackett and Lehn, 1997). We discuss these hypotheses in greater detail below.

To fully account for the observed difference between the parrot and toucan genetic divergences, Pteroglossus mtDNA sequences would have to be evolving at approximately half the rate of Pionopsitta mtDNA. Due to the lack of fossil data for Neotropical parrots and toucans, it is impossible to adjust their "molecular clocks" to take into account lineage-specific rate variation, as recommended by Rambaut and Bromham (1998). The $2 \%$ mtDNA sequence divergence per million years rate appears to hold across distantly related avian taxa-e.g., geese (Shields and Wilson, 1987) and Hawai'ian honeycreepers (Tarr and Fleischer, 1993) - but there is some evidence of lineage-specific rate variation in birds (see Lovette, 2004), e.g., due to generation time (Mooers and Harvey, 1994) and population size (Johnson and Seger, 2001). Our comparison of $K_{\mathrm{A}}$ and $K_{\mathrm{S}}$ shows that the accumulation of per-site non-synonymous changes relative to synonymous ones is more rapid in Pteroglossus than in Pionopsitta. According to Ohta's (1973) "nearly neutral" model of molecular evolution, this could result from consistently smaller population sizes in Pteroglos- sus compared to Pionopsitta; such an effect was found in multiple comparisons of island vs. mainland bird lineages (Johnson and Seger, 2001)s. However, neither the difference in $K_{\mathrm{A}}$ vs. $K_{\mathrm{S}}$ relationships, nor an inferred difference in population sizes, explain the observation of greater divergences in the parrot genus. Allozyme data for Pteroglossus do not suggest that toucans have particularly low levels of genetic variation within populations, which might have explained the low levels of variation among populations and species (Hackett and Lehn, 1997). In sum, while we do not have evidence of selection resulting in a higher rate of molecular evolution in Pionopsitta, or of low levels of genetic variation in Pteroglossus, we cannot reject the hypothesis that Pionopsitta and Pteroglossus have twofold different rates of mtDNA evolution.

A particular animal's dispersal abilities, tolerance of open habitats, home range size, etc., are likely to affect its response to the presence of a barrier such as a river, grassland habitat, or a mountain range. As emphasized by Bermingham and Avise (1986), barriers to dispersal may increase and decrease in permeability as a function of fluctuating climate change (e.g., changes in coastal shelf area, forest elevation, river flow, and morphology) and the dispersal characteristics of organisms. Pionopsitta parrots and Pteroglossus toucans are broadly similar in several ways. Their body size is similar (100$140 \mathrm{~g}$ in Pionopsitta; 125-180 g in Pteroglossus), both groups live in the forest canopy and are primarily frugivorous, and both are cavity-nesters. Neither group is restricted to closed-canopy forest; members of both genera also occur in second-growth, gallery forest, savannah, and clearings with scattered trees (see Section 1). These broad similarities suggest that members of the two genera would have a similar propensity to cross geographic barriers, however, the natural history of these birds is poorly known and it is quite possible that, for example, Pteroglossus toucans are better dispersers than Pionopsitta parrots. A greater dispersal ability could increase the "permeability" of an emerging barrier for toucans compared to parrots, and result in the observed differences between estimated timing of vicariance events.

According to the third hypothesis, outlined by Hackett and Lehn (1997) in their paper on genetic differentiation in Pteroglossus, the amount of genetic structuring of populations preceding speciation events ("initial genetic conditions") influences the amount of genetic differentiation between species after speciation (see also Arbogast et al., 2002). Populations characterized by high levels of gene flow (and consequently little phylogeographic structure) would, upon being separated due to a vicariance event, give rise to species initially separated by a relatively small genetic distances. On the other hand, an organism with populations that experience low levels of gene flow would be more genetically structured, and 
following a vicariance event, the genetic distance between descendant species would be, from the beginning, relatively large. In a simulation study of rates of nucleotide substitution and lineage sorting of mtDNA, Hoelzer et al. (1998) found that in subdivided populations, rates and patterns of migration can strongly affect the length of the lineage sorting period. Unfortunately, there are no studies of dispersal or within-population genetic differentiation in either Pteroglossus or Pionopsitta, making it difficult to evaluate this hypothesis.

The second and third hypotheses are likely to be related, and the mtDNA phylogenies and distribution patterns for the two genera are consistent with both. The large amount of sympatry in the Pteroglossus, particularly between relatively older lineages, is probably due to dispersal and colonization of new geographic areas following allopatric speciation. That post-speciation dispersal seems to have occurred more in Pteroglossus than in Pionopsitta suggests that the toucans move around more. In addition to resulting in post-speciation sympatry, this would also tend to reduce population genetic structuring, which would lead to lower levels of genetic divergence among species. Conversely, the allopatry of Pionopsitta species suggests that these parrots may, for social or ecological reasons, have a reduced tendency to disperse, which would also tend to increase population genetic structure, in turn resulting in the greater genetic divergences among species that we observe. Stronger competitive exclusion between congeners in parrots compared with toucans could also result in lack of sympatry in the parrots, but would not explain the discrepancy between genetic distances between parrot and toucan lineages that presumably diverged due to the same vicariance event.

The cyclical climatic changes associated with largescale variations in the Northern hemisphere's ice cover are thought to have been particularly severe during the last 0.9 mya of the late Pleistocene (Stanley and Ruddiman, 1995; Webb and Bartlein, 1992), during which expansions and contractions of forest cover may have promoted allopatric speciation as outlined by the Pleistocene refuge hypothesis. If the divergence time estimates yielded by our data are taken at face value, both Pionopsitta and Pteroglossus began to diversify prior to the start of the Pleistocene 2.5 mya, and well before the onset of the late-Pleistocene climatic cycles (Fig. 7). In particular, the lineage divergences corresponding to the Serra do Mar and cis-/trans-Andean vicariance events occurred more than 2.5 mya. The timing of the final uplift of the Northern Andes' Eastern Cordillera, which occurred rapidly between 2 and 5 mya (Gregory-Wodzicki, 2000), brackets the estimated dates of the cis-/transAndean splits in Pionopsitta and Pteroglossus. Our data on the timing of the upper/lower Amazonian vicariance event are ambiguous, with the Pionopsitta data suggesting that it occurred over 3 mya, but the Pteroglossus data placing it squarely within the Pleistocene at about 1 mya. These estimates also apply to the Chocó /Central America divergence, which apparently occurred following the formation of the Isthmus of Panama approximately 3.5 mya (Coates, 1997) The formation of the modern Amazon River during the late Miocene (Lundberg et al., 1998) antedates the diversification among Amazonian taxa in the two genera that we studied, so was probably not the main cause of diversification among; however, our sampling is not detailed enough to carefully test the riverine barrier hypothesis. Data from both genera indicate that the divergence of Guyanan lineages and the diversification of taxa from upper Amazonia occurred within the past 2 mya.

In summary, even given the discrepancies between area divergence times estimated using data from the two genera that we studied, it is clear that Pleistocene climatic and habitat shifts alone cannot account for the diversification of these taxa. The concordance between the two genera in the relative timing of biogeographic splits strongly suggests, as have previous morphologybased analyses (Cracraft and Prum, 1988; Prum, 1988), that the same vicariance events shaped the biogeographic history of both lineages. However, the reasons for the differences between genera in the estimated dates of these vicariance events are difficult to determine, and underscore some of the difficulties of using a molecular clock. The accuracy of molecular clocks stands to be greatly improved by new rate calibrations for a wider range of taxa and the application of new analytical methods (Lovette, 2004). Studies such as ours would also benefit from additional information on the behavior and ecology (e.g., dispersal biology) of the taxa in question, since such data are important for interpreting biogeographic patterns, which are driven by ecological processes.

\section{Acknowledgments}

This study would not have been possible without the samples that were made available to us by the collectors and curators affiliated with the following institutions: the Academy of Natural Sciences, Philadelphia; the Genetic Resources Collection at the Louisiana State University Museum of Natural Science; the National Museum of Natural History; the University of Kansas Museum of Natural History; the Field Museum of Natural History; and Jerry Jennings (Emerald Forest Bird Gardens). We thank M. González for laboratory assistance, and M. Leone for handling permit paperwork. For helpful comments on the manuscript, we thank J. Malvarez, M. Miller, J. Weckstein, and an anonymous reviewer. Funding was provided by a Smithsonian Institution Post-doctoral Fellowship to J.R.E. and the Smithsonian Tropical Research Institute's Molecular Evolution Program. 


\section{References}

Arbogast, B.S., Edwards, S.V., Wakeley, J., Beerli, P., Slowinski, J.B., 2002. Estimating divergence times from molecular data on phylogenetic and population genetic timescales. Ann. Rev. Ecol. Syst. 33, 707-740.

Barraclough, T.G., Vogler, A.P., 2000. Detecting the geographical pattern of speciation from species-level phylogenies. Am. Nat. 155, 419-434.

Barker, F.K., Lanyon, S.M., 2000. The impact of parsimony weighting schemes on inferred relationships among toucans and Neotropical barbets (Aves: Piciformes). Mol. Phylogenet. Evol. 15, 215-234.

Bates, J.M., Hackett, S.J., Cracraft, J., 1998. Area-relationships in the Neotropical lowlands: an hypothesis based on raw distributions of Passerine birds. J. Biogeogr. 25, 783-793.

Bates, J.M., Hackett, S.J., Goerck, J.M., 1999. High levels of mitochondrial DNA differentiation in two lineages of antbirds (Drymophila and Hypocnemis). Auk 116, 1093-1106.

Bermingham, E., Avise, J.C., 1986. Molecular zoogeography of freshwater fishes in the southeastern United States. Genetics 113, 939965.

Burns, K.J., 1997. Molecular systematics of Tanagers (Thraupinae): evolution and biogeography of a diverse radiation of Neotropical birds. Mol. Phylogenet. Evol. 8, 334-348.

Bush, M.B., 1994. Amazonian speciation: a necessarily complex model. J. Biogeogr. 21, 5-17.

Capparella, A.P., 1988. Genetic variation in Neotropical birds: implications for the speciation process. In: Quellet, H. (Ed.), Acta XIX Congressus Internationalis Ornithologici. XIX International Ornithological Congress, Ottawa, pp. 2562-2572.

Coates, A.G., 1997. The forging of Central America. In: Coates, A.G. (Ed.), Central America: A Natural and Cultural History. Yale University Press, New Haven, pp. 1-37.

Cortés-Ortíz, L, Bermingham, E., Rico, C., Rodríguez-Luna, E., Sampaio, I., Ruiz-García, M., 2003. Molecular systematics and biogeography of the Neotropical monkey genus Alouatta. Mol. Phylogenet. Evol. 26, 64-81.

Cracraft, J., 1985. Historical biogeography and patterns of differentiation within the South American avifauna: areas of endemism. Ornithol. Monogr. 36, 49-84.

Cracraft, J., Prum, R.O., 1988. Patterns and processes of diversification: speciation and historical congruence in some Neotropical birds. Evolution 42, 603-620.

Eberhard, J.R., Bermingham, E., 2004. Phylogeny and biogeography of the Amazona ochrocephala (Aves: Psittacidae) complex. Auk 121, 318-332.

Edwards, S.V., Beerli, P., 2000. Perspective: gene divergence, population divergence, and the variance in coalescence time in phylogeographic studies. Evolution 54, 1839-1854.

Endler, J.A., 1982. Pleistocene forest refuges: fact or fancy?. In: Prance, G.T. (Ed.), Biological Diversification in the Tropics. Columbia University Press, New York, pp. 641-657.

Felsenstein, J., 1981. Evolutionary trees from DNA sequences: a maximum likelihood approach. J. Mol. Evol. 17, 368-376.

Forshaw, J.M., 1989. Parrots of the World. Landsdowne Editions, Willoughby, Australia.

Friesen, V.L, Congdon, B.C., Walsh, H.E., Birt, T.P., 1997. Intron variation in marbled murrelets detected using analyses of singlestranded conformational polymorphisms. Mol. Ecol. 6, 1047-1058.

Gaban-Lima, R., Raposo, M.A., Höfling, E., 2002. Description of a new species of Pionopsitta (Aves: Psittacidae) endemic to Brazil. Auk 119 (3), 815-819.

Gregory-Wodzicki, K.M., 2000. Uplift history of the Central and Northern Andes: a review. Geol. Soc. America Bull. 112, 1091-1105.

Gyldenstope, N., 1951. The ornithology of the Rio Purús region in western Brazil. Arkiv. Zool. 2, 1-320.
Hackett, S.J., 1993. Phylogenetic and biogeographic relationships in the Neotropical genus Gymnopithys (Formicariidae). Wilson Bull. $105,301-315$.

Hackett, S.J., 1995. Molecular systematics and zoogeography of flowerpiercers in the Diglossa baritula complex. Auk 112, 156-170.

Hackett, S.J., 1996. Molecular phylogenetics and biogeography of tanagers in the genus Ramphocelus (Aves). Mol. Phylogenet. Evol. 5, 368-382.

Hackett, S.J., Lehn, C.A., 1997. Lack of genetic divergence in a genus (Pteroglossus) of Neotropical birds: the connection between lifehistory characteristics and levels of genetic divergence. Ornithol. Monogr. 48, 267-279.

Hackett, S.J., Rosenberg, K.V., 1990. Comparisons of phenotypic and genetic differentiation in South American antwrens (Formicariidae). Auk 107, 473-489.

Haffer, J., 1969. Speciation in Amazonian forest birds. Science 165, 131-137.

Haffer, J., 1974. Avian Speciation in Tropical South America. Nuttall Ornithological Club, Cambridge, MA.

Haffer, J., 1997. Alternative models of vertebrate speciation in Amazonia: an overview. Biodiv. Conserv. 6, 451-476.

Hilty, S.L., Brown, W.L., 1986. Birds of Colombia. Princeton University Press, Princeton.

Hoelzer, G.A., Wallman, J., Melnick, D.J., 1998. The effects of social structure, geographical structure, and population size on the evolution of mitochondrial DNA: II. Molecular clocks and lineage sorting period. J. Mol. Evol. 47, 21-31.

Huelsenbeck, J.P., Ronquist, F., 2001. MrBayes: Bayesian inference of phylogeny. Bioinformatics 17, 754-755.

Johnson, K.P., Seger, J., 2001. Elevated rates of nonsynonymous substitution in island birds. Mol. Biol. Evol. 18, 874-881.

Juniper, T., Parr, M., 1998. Parrots: A Guide to Parrots of the World. Yale University Press, New Haven, CT.

Li, W.H., 1993. Unbiased estimation of the rates of synonymous and nonsynonymous substitution. J. Mol. Evol. 36, 96-99.

Losos, J.B., Glor, R.E., 2003. Phylogenetic comparative methods and the geography of speciation. Trends Ecol. Evol. 18, 220-227.

Lovette, I.J., 2004. Mitochondrial dating ad mixed support for the " $2 \%$ " rule in birds. Auk 121, 1-6.

Lundberg, J.G., Maeshal, L.G., Guerrero, J., Horton, B., Malabarba, C.S.L., Wesselingh, F., 1998. The stage of Neotropical fish diversification: a history of tropical South American rivers. In: Malabarba, L.R., Reis, R.E., Vari, R.P., Lucena, Z.M., Lucena, C.A.S. (Eds.), Phylogeny and Classification of Neotropical Fishes. EDIPUCRS, Porto Alegre, pp. 13-48.

Marks, B.D., Hackett, S.J., Capparella, A.P., 2002. Historical relationships among Neotropical lowland forest areas of endemism as determined by mitochondrial DNA sequence variation within the Wedge-billed Woodcreeper (Aves: Dendrocolaptidae: Glyphorynchus spirurus). Mol. Phylogenet. Evol. 24, 153-167.

Meyer de Schauensee, R., Phelps Jr., W.H., 1978. Birds of Venezuela. Princeton University Press, Princeton.

Mooers, A.Ø., Harvey, P.H., 1994. Metabolic rate, generation time, and the rate of molecular evolution in birds. Mol. Phylogenet. Evol. 3, 344-350.

Murray, M.G., Thompson, W.F., 1980. Rapid isolation of high molecular weight plant DNA. Nucleic Acids Res. 8, 4321-4325.

Nores, M., 1999. An alternative hypothesis for the origin of Amazonian bird diversity. J. Biogeogr. 26, 475-485.

Ohta, T., 1973. Slightly deleterious mutant substitutions in evolution. Nature 246, 96-98.

Page, R.D.M., 1994. Parallel phylogenies: reconstructing the history of host-parasite phylogenies. Cladistics 10, 155-173.

Page, R.D.M., 1995. TreeMap program, platforms: Microsoft Windows, Macintosh. Available from: <http://taxonomy.zoology.gla.ac.uk/rod/treemap.html>. 
Page, R.D.M., Charleston, M.A., 1998. Trees within trees: phylogeny and historical associations. Trends Ecol. Evol. 13, 356-359.

Palumbi, S.R., 1996. Nucleic acids II: the polymerase chain reaction. In: Hillis, D.M., Moritz, C., Mable, B.K. (Eds.), Molecular Systematics. Sinauer Associates, Sunderland, MA.

Pamilo, P., Bianchi, N.O., 1993. Evolution of the Zfx and Zfy genes: rates and interdependence between genes. Mol. Biol. Evol. 10, 271281.

Posada, D., Crandall, K.A, 1998. Modeltest: testing the model of DNA substitution. Bioinformatics 14 (9), 817-818.

Prance, G.T., 1982. Biological Diversification in the Tropics. Columbia University Press, New York.

Prum, R.O., 1988. Historical relationships amog avian forest areas of endemism in the Neotropics. In: Quellet, H. (Ed.), Acta XIX Congressus Internationalis Ornithologici. XIX International Ornithological Congress, Ottawa, pp. 2562-2572.

Rambaut, A., Bromham, L., 1998. Estimating divergence dates from molecular sequences. Mol. Biol. Evol. 15, 442-448.

Remsen Jr., J.V., Hyde, M.A., Chapman, A., 1993. Diets of Neotropical trogons, motmots, barbets and toucans. Condor 95, 178-192.

Ridgely, R.S., Greenfield, P.J., 2001. The Birds of Ecuador. Cornell University Press, Ithaca.

Ridgely, R.S., Gwynne Jr., J.A, 1989. Birds of Panama. Princeton University Press, Princeton.

Rodriguez, F., Oliver, J.F., Marin, A., Medina, J.R., 1990. The general stochastic model of nucleotide substitutions. J. Theor. Biol. 142, 485-501.

Seutin, G., Brawn, J., Ricklefs, R.E., Bermingham, E., 1993. Genetic divergence among populations of a tropical passerine, the Streaked Saltator (Saltator albicollis). Auk 110, 117-126.

Shields, G.F., Wilson, A.C., 1987. Calibration of mitochondrial DNA evolution in geese. J. Mol. Evol. 24, 212-217.
Shimodaira, H., Hasegawa, M., 1999. Multiple comparisons of log-likelihoods with applications to phylogenetic inference. Mol. Biol. Evol. 16, 1114-1116.

Sibley, C.G., Monroe, B.L., 1990. Distribution and Taxonomy of Birds of the World. Yale University Press, New Haven.

Silva, J.M.C., da Oren, D.C., 1996. Application of parsimony analysis of endemicity in Amazonian biogeography: an example with primates. Biol. J. Linn. Soc. 59, 427-437.

Stanley, S.M., Ruddiman, W.F., 1995. Neogene ice age in the north Atlantic region: climatic changes, biotic effects, and forcing factors. In: Effects of Past Global Changes on Life (Board on Earth Sciences and Resources, Commission on Geosciences, and Resources, National Research Council). National Academy Press, Washington, DC.

Swofford, D.L., 1999. PAUP* Phylogenetic Analysis Using Parsimony (* and Other Methods). Version 4. Sinauer Associates, Sunderland.

Swofford, D.L., Olsen, G.J., Waddell, P.J., Hillis, D.M., 1996. Phylogenetic inference. In: Hillis, D.M., Moritz, C., Mable, B.K. (Eds.), Molecular Systematics. Sinauer Associates, Sunderland, MA, pp. 407-514.

Tamura, K., Nei, M., 1993. Estimation of the number of nucleotide substitutions in the control region of mitochondrial DNA in humans and chimpanzees. Mol. Biol. Evol. 10, 512-526.

Tarr, C.L., Fleischer, R.C., 1993. Mitochondrial DNA variation and evolutionary relationships in the Amakihi complex. Auk 110 (4), 825-831.

Tuomisto, H., Ruokolainen, K., 1995. The role of ecological knowledge in explaining biogeography and biodiversity in Amazonia. Biodiv. Conserv. 6, 347-357.

Webb III, T., Bartlein, P.J., 1992. Global changes during the last 3 million years: climatic controls and biotic responses. Ann. Rev. Ecol. Syst. 23, 141-173. 